\title{
Hortonian Overland Flow, Hillslope Morphology and Stream Power I: Spatial Energy Distributions and Steady-state Power Maxima
}

\author{
Samuel Schroers ${ }^{1}$, Olivier Eiff ${ }^{1}$, Axel Kleidon ${ }^{2}$, Jan. Wienhöfer ${ }^{1}$, Erwin Zehe $^{1}$ \\ 'Institute of Water Resources and River Basin Management, Karlsruhe Institute of Technology - KIT, Karlsruhe, Germany \\ 5 2Max-Planck Institute for Biogeochemistry, Hans-Knöll-Str. 10, 07745 Jena, Germany
}

Correspondence to: S. Schroers (samuel.schroers@kit.edu)

\begin{abstract}
Recent developments in hydrology have led to a new perspective on runoff processes, extending beyond the classical mass dynamics of water in a catchment. For instance, stream flow has been analyzed in a thermodynamic framework, which allows the incorporation of two additional physical laws and enhances our understanding of catchments as open environmental

10 systems. Related investigations suggested that energetic extremal principles might constrain hydrological processes, because the latter are associated with conversions and dissipation of free energy. Here we expand this thermodynamic perspective by exploring how macro and micro hillslope structures control the free energy balance of Hortonian overland flow. This may ultimately help understanding why these structures have evolved to their present shape. To this end, we develop a general theory of surface runoff and of the related conversion of geopotential energy gradients into other forms of energy, particularly

15 kinetic energy as driver of erosion and sediment transport. We then use this framework to analyze how combinations of typical hillslopes profiles and width distributions control the spatial patterns of steady state stream power and energy dissipation along the flow path. Additionally, we provide a first order estimate whether and when rills reduce the overall energy dissipation compared to sheet flow. Finally, we relate accumulated stream power of linear hillslopes to slope angles, closing the loop to Horton's original formulation of erosion force. The analytical analysis of stream power reveals that the common formulation,

20 a function of the depth-discharge product is a reduced version of the more general equations if we neglect changes in velocity and discharge in space. The full equations of stream power result in maximum energy fluxes in space for sinusoidal and exponential hillslope profiles, while linear and negative exponential forms unlimitedly increase these fluxes in the downstream direction. Depending on geometry, rill flow increases or decreases kinetic energy fluxes downslope, effectively counteracting or increasing the dissipation of potential energy. For accumulated power in space for steady state runoff, we find that on linear 25 hillslopes a slope angle of $45^{\circ}$ maximizes the conversion of potential energy into dissipation and an angle of $35^{\circ}$ maximizes the conversion of potential energy into kinetic energy.
\end{abstract}




\section{Introduction}

30 Surface runoff processes are of key importance to stream flow generation, flash floods and erosion processes. From an energycentered perspective, surface runoff formation and concentration are just two of the varieties of manifestations of how energy gradients in open environmental systems emerge and dissipate. Effective rainfall adds potential energy to the hillslope surface, causing a potential energy difference between upslope catchment areas and the stream channel. A small part of this potential energy gradient is converted into kinetic energy of overland flow, while the vast majority is dissipated via friction into heat

35 (Loritz et al., 2019). The morphology and width function of hillslopes are expected to play an important role, as they reflect different geomorphological stages and correspond to different locations of the hillslope within the catchment (Kirkby, 1971). For instance, early-stage negative exponentially shaped hillslopes are formed by soil creep, while later stage linear slope profiles result of soil wash with increasing gullying, which ultimately leads to the characteristic exponential profiles of rivers (Kirkby, 1971; Leopold and Langbein, 1962). Similarly, overland flow accumulation of hillslopes in upstream catchment

40 ranges is mostly characterised by a downslope convergence (Troch et al., 2004), while hillslopes in downstream parts of the catchment tend to diverge (Berne et al., 2005). This suggests that form and surface geometry reflect the past overland flow functionalities and erosion processes of hillslopes (Kirkby, 1971). The pressing question is how to quantify these relations between form, geomorphological age and past overland flow functioning? Here, we propose that a thermodynamic perspective on surface runoff and the related energy conversions in space and time hold clues to answers.

45 The application of thermodynamic laws and energetic concepts to surface runoff processes is of course not new (Yang, 1971; Kleidon et al., 2013). It dates back to the work by Leopold and Langbein (1962) on the role of entropy in the evolution of landforms. Howard (1971, cited in Howard 1990) suggested that river junctions minimize stream power. Much effort has been put into the understanding of the formation and evolution of river networks, and whether they form in accordance with energetic minimization or maximization principles (Rodiguez-Iturbe et al., 1992; Rinaldo et al., 1992; Howard, 1990; Rinaldo, 1999; Kleidon et al., 2013). This was largely inspired by the obvious structural similarity of river networks to other networks in nature such as the cardiovascular system in the human body (West et al., 1997; Zamir, 1976). Especially the idea that nonephemeral drainage patterns are a result of minimization of energy dissipation (Howard, 1990; Rodriguez-Iturbe et al., 1992) or maximization of power in sediment transport (Kleidon et al., 2013) has been tested several times. This idea relates to the more general hypothesis that open hydrological systems evolve to a meta-stable, thermodynamically optimal configuration, as

55 proposed in a range of studies (Zehe et al., 2013; Kleidon et al., 2014; Zhang and Savenije, 2018). Hillslope-scale rill networks are another prime manifestation of such networks and their emergence and topology affect the aforementioned conversion and dissipation of potential energy into kinetic energy and heat. The common assumption here is that concentrated rill flow reduces the volume specific dissipative loss due to a larger hydraulic radius (Berkowitz and Zehe, 2020), which causes larger flow velocities compared to sheet flow. The geometry and topology of these drainage networks are however transient, as a response 60 to transient flows of water and sediments, and these networks develop in a self-reinforcing manner (Gómez et al., 2003; RiekeZapp and Nearing, 2005b; Berger et al., 2010). Starting at the hillslope top continuing downstream micro rills emerge at some 
critical distance, and usually continue in parallel for some time before they merge into larger rills, sometimes drifting apart again and remerging until they might even expand into larger gullies (Achten et al., 2008; Faulkner, 2008) and finally the river channel. This transitional emergence of a structured drainage network was firstly stated in Playfair's Law (cited in Horton,

65 1945) and has since then been observed in a variety of studies (Emmett, 1970; Abrahams, 1994). One might hence state that the current structure of the hillslope surface including the rill network at one scale, or the catchment and river network at the next higher scale is a fingerprint of the physical work overland flow has performed on the sediments up to then (Paik and Kumar, 2010). A driving question in this context is whether hillslope scale rill systems (Favis-Mortlock et al., 2000) and river networks evolve towards a meta-stable energetically optimal configuration, which minimizes overall energy dissipation- or energy expenditure (Rodriguez-Iturbe et al., 1992, Ijjász-Vásquez et al., 1993) and thus maximizes stream power.

Motivated by their similarity to river networks, several studies tested whether hillslope scale rill networks develop in accordance with the minimum energy expenditure theory of river systems (Gómez et al., 2003; Rieke-Zapp and Nearing, 2005b; Berger et al., 2010). In line with Rodrigo-Iturbe et al. (1992) these studies assume that the flow velocity tends to be uniform throughout the rill network and discharge is hence proportional to the drainage area. Optimal Channel Network (OCN) models assume a contributing area equal to the discharge of a channel segment, which implies constant velocity, and therefore focus on the spatial arrangement of these channel segments with regard to optimality. However, the assumption of a constant velocity has been substantially criticized (Paik and Kumar, 2010). This is because studies of rivers (Ibbitt, 1997) and particularly rill systems (Emmett, 1970; Parsons et al., 1990) as well as laboratory experiments (Shao et al., 2005) showed that the transitions of sheet- to rill- to river flow and the increasing downslope flow accumulation lead to an accelerated flow velocity. This implies that less energy per unit area and per unit discharge is dissipated and clearly speaks against the idea of an equal energy expenditure per unit area. Hillslopes, as mass-accumulating systems, are furthermore characterized by a downslope transition of sheet to rill flow. We thus argue that not only the spatial arrangement and topology of the rill network but also the size and arrangement of contributing inter-rill areas (and their secondary side slopes) in concert with the hillslope form and its width function control Hortonian overland flow accumulation, its speed, and the related energy conversions

85 (Parsons et al., 1990). This implies that a hillslope has several options to reach an energetically optimal configuration in time and space, rills and the contributing area, form, and width function may adjust.

The main objective of this study is hence to explore the spatially distributed nature of Hortonian overland flow accumulation and the related energy conversions. Instead of exclusively focusing on the role of networks and their spatial arrangement, we focus on the entire hillslope i.e., how different hillslope forms and width functions affect kinetic energy generation and potential energy dissipation in response to different effective rainfall forcings. We propose that despite the similarity of hillslope and river runoff, their energetic functioning is distinctly different. This is largely because river elements are mainly fed from the upstream discharge (Kleidon et al., 2013) while hillslope elements receive substantial water masses through rainfall input and upslope runon. We will show that the latter causes a trade-off in the potential energy of overland flow as an increasing mass of water flows along a continuously declining geopotential. These antagonistic effects imply that potential energy of overland flow peaks at a distinct point in space along the hillslope. To show this, we present a general theory, which 
puts overland flow on hillslopes into an energy-centred, thermodynamic framework by taking advantage of recent advances to understand energy conversion processes of Earth systems (Kleidon, 2016). Based on this theory we explore how the spatial location and magnitude of the power and potential energy maxima depend on effective rainfall intensity, hillslope form and its width function during steady state and discuss the implications for hillslope morphology. This aspect requires establishing a link between the free energy balance of overland flow, its attacking forces and critical shear stress, and thus its implication for erosion processes. In this context, critical shear stress is defined as a threshold that triggers movement of soil particles (Zehe and Sivapalan, 2009) by surface runoff. As forces on the bed material relate to gradients in potential energy along a flow path, the space-time distribution of potential energy, its' conversion into kinetic energy (power), and its dissipation are directly linked to this force. Horton (1945) used this connection and developed a theory relating energy dissipation and bed shear stress for steady state systems with negligible mass accumulation such as rivers. The revised equation known today as the depthslope product (Bangold, 1966) is applied in many erosion prediction models for the calculation of bed shear stress. Here, we show that our theory is in line with these works and how it is applicable beyond. In a related study, we plan to expand this theory and analysis to transient conditions for lumped and later on spatially distributed hillslope system, exploring the role of rill networks and spatially heterogeneous roughness elements, using numerical models.

\section{Theory}

\subsection{The hillslope surface as open thermodynamic system}

To frame surface flow processes into a thermodynamic perspective we define the surface of a hillslope as an open thermodynamic system (OTS) (Kleidon, 2016; Zehe et al., 2013). In this sense, the hillslope exchanges mass, momentum, energy and entropy with its environment (Fig. 1 and 2) Rainfall adds mass at a certain height and thus free energy in the form

115 of potential energy along the upper system boundary at a certain altitude and at the lower boundary mass, and free energy leaves the system due to surface runoff or via infiltration as subsurface flow (Zehe et al., 2013). In the following, we elaborate the joint mass, energy and momentum budgets of overland flow systems from a thermodynamic point of view. (see e.g. Kleidon et al., 2013; Kleidon, 2016).

Table 1: Overview of the different symbols used in this study

\begin{tabular}{cll}
\hline symbol & unit & description \\
\hline $\boldsymbol{U}$ & {$\left[\mathrm{kg} \mathrm{m}^{2} \mathrm{~s}^{-2}\right]$} & internal energy of a thermodynamic system \\
\hline $\boldsymbol{W}$ & {$\left[\mathrm{kg} \mathrm{m}^{2} \mathrm{~s}^{-2}\right]$} & available energy to perform work by the thermodynamic system \\
\hline $\boldsymbol{H}$ & {$\left[\mathrm{kg} \mathrm{m}^{2} \mathrm{~s}^{-2}\right]$} & thermal energy of the thermodynamic system \\
\hline $\boldsymbol{E}_{\boldsymbol{f}}^{\boldsymbol{p e}}$ & {$\left[\mathrm{kg} \mathrm{m} \mathrm{s}^{-2}\right]$} & potential energy of the water flow \\
\hline $\boldsymbol{E}_{\boldsymbol{f}}^{\boldsymbol{k e}}$ & {$\left[\mathrm{kg} \mathrm{m} \mathrm{s}^{-2}\right]$} & kinetic energy of the water flow \\
\hline $\boldsymbol{J}_{\boldsymbol{f}, \boldsymbol{i n}}^{\boldsymbol{e}}$ & {$\left[\mathrm{kg} \mathrm{m} \mathrm{s}^{-3}\right]$} & potential energy flux entering the system \\
\hline $\boldsymbol{J}_{\boldsymbol{f}, \boldsymbol{o u t}}^{\boldsymbol{p e}}$ & {$\left[\mathrm{kg} \mathrm{m} \mathrm{s}^{-3}\right]$} & potential energy flux leaving the system \\
\hline
\end{tabular}




\begin{tabular}{|c|c|c|}
\hline$J_{f, \text { in }}^{k e}$ & {$\left[\mathrm{~kg} \mathrm{~m} \mathrm{~s}^{-3}\right]$} & kinetic energy flux into entering system \\
\hline$J_{f, o u t}^{k e}$ & {$\left[\mathrm{~kg} \mathrm{~m} \mathrm{~s}^{-3}\right]$} & kinetic energy flux leaving the system \\
\hline$J_{P, \text { in }}^{p e}$ & {$\left[\mathrm{~kg} \mathrm{~m} \mathrm{~s}^{-3}\right]$} & precipitation entering the system as potential energy flux \\
\hline$J_{\text {inf,out }}^{p e}$ & {$\left[\mathrm{~kg} \mathrm{~m} \mathrm{~s}^{-3}\right]$} & infiltration leaving the system as potential energy flux \\
\hline$P_{f}$ & {$\left[\mathrm{~kg} \mathrm{~m} \mathrm{~s}^{-3}\right]$} & power to create kinetic energy of system \\
\hline$D_{f}$ & {$\left[\mathrm{~kg} \mathrm{~m} \mathrm{~s}^{-3}\right]$} & dissipation of free energy of flow into different kind of energy \\
\hline$m$ & {$[\mathrm{~kg}]$} & mass \\
\hline$v$ & {$\left[\mathrm{~m} \mathrm{~s}^{-1}\right]$} & velocity of runoff, parallel to bed slope \\
\hline$v_{T}$ & {$\left[\mathrm{~m} \mathrm{~s}^{-1}\right]$} & vertical fraction of $\mathrm{v}$ \\
\hline$F_{\text {acc }}$ & {$\left[\mathrm{kg} \mathrm{m} \mathrm{s}^{-2}\right]$} & acceleration force \\
\hline$F_{d}$ & {$\left[\mathrm{~kg} \mathrm{~m} \mathrm{~s}^{-2}\right]$} & drag force \\
\hline$J_{o u t}^{p}$ & {$\left[\mathrm{~kg} \mathrm{~m} \mathrm{~s}^{-2}\right]$} & momentum output of system \\
\hline$J_{f}^{p e}$ & {$\left[\mathrm{~kg} \mathrm{~m}^{2} \mathrm{~s}^{-3}\right]$} & advective potential energy flux \\
\hline$J_{f}^{k e}$ & {$\left[\mathrm{~kg} \mathrm{~m}^{2} \mathrm{~s}^{-3}\right]$} & advective kinetic energy flux \\
\hline$E_{s p}^{p e}$ & {$\left[\mathrm{~m}^{2} \mathrm{~s}^{-2}\right]$} & specific potential energy \\
\hline$E_{s p}^{k e}$ & {$\left[\mathrm{~m}^{2} \mathrm{~s}^{-2}\right]$} & specific kinetic energy \\
\hline$\rho$ & {$\left[\mathrm{kg} \mathrm{m}^{-3}\right]$} & density of water with value of 1000 \\
\hline$g$ & {$\left[\mathrm{~m} \mathrm{~s}^{-2}\right]$} & gravitational acceleration with value of 9.81 \\
\hline$Q$ & {$\left[\mathrm{~m}^{3} \mathrm{~s}^{-1}\right]$} & discharge \\
\hline $\boldsymbol{h}$ & {$[\mathrm{m}]$} & vertical distance of centre of mass of system to hillslope end \\
\hline $\boldsymbol{b}$ & {$[\mathrm{m}]$} & hillslope width \\
\hline$P_{\text {eff }}$ & {$\left[\mathrm{m} \mathrm{s}^{-1}\right]$} & effective rainfall intensity \\
\hline$I$ & {$\left[\mathrm{~m} \mathrm{~s}^{-1}\right]$} & rainfall intensity \\
\hline $\boldsymbol{H}$ & {$[\mathrm{m}]$} & water column depth of surface runoff \\
\hline $\boldsymbol{n}$ & {$\left[\mathrm{m}^{-1 / 3} \mathrm{~s}\right]$} & manning coefficient \\
\hline$S$ & {$[-]$} & slope of bed level \\
\hline$z$ & {$\left[\mathrm{~m}^{2} \mathrm{~s}^{2}\right]$} & geopotential of bed level to reference level \\
\hline$X_{H S}$ & {$[\mathrm{~m}]$} & length of hillslope, parallel to reference surface \\
\hline$L_{H S}$ & {$[\mathrm{~m}]$} & length of hillslope, parallel to bed level \\
\hline $\boldsymbol{R}$ & {$[\mathrm{m}]$} & hydraulic radius \\
\hline $\boldsymbol{A}$ & {$\left[\mathrm{m}^{2}\right]$} & wetted area of discharge \\
\hline$r$ & {$[\mathrm{~m}]$} & radius of semi-circled rills \\
\hline$m$ & {$[-]$} & number of semi-circled rills \\
\hline$d_{\text {oTS }}$ & {$[\mathrm{m}]$} & sloped flow path length of surface runoff \\
\hline$\tau_{b}$ & {$\left[\mathrm{~kg} \mathrm{~m}^{-1} \mathrm{~s}^{-2}\right]$} & bed shear stress \\
\hline
\end{tabular}




\subsection{Free energy and momentum balance in overland flow}

With the first law of thermodynamics we express energy conservation of surface runoff in the following form:

$$
\frac{d U}{d t}=\frac{d(H)}{d t}+\frac{d W}{d t}
$$

which states that a change in the internal energy $\mathrm{U}$ [Joule] of a system consists of the transfer of heat $\mathrm{H}$ [Joule] to the system plus the amount of work W [Joule] performed by the system. Here, we add performed work to the internal energy, as in an

open environmental system the amount of energy $d W$ does not leave the system but rather is converted into some other kind of energy that stays inside the system (Kleidon, 2013). Note that the capacity of a system to perform work is equivalent to the term "free energy", whereas heat is associated with the dissipation of free energy and production of thermal entropy. The latter reflects the second law of thermodynamics, which states that entropy is produced during irreversible processes. The free energy of surface runoff at any point on the hillslope corresponds to the sum of its potential and kinetic energy if we neglect pressure work (i.e. assuming constant pressure), mechanical work (i.e. no shaft work such as pumps and turbines) and chemical energies. We apply for each considered energy type Eq. (1), meaning an influx of energy causes a gradient, which can be depleted to create another type of energy. For potential energy we consider the part which corresponds to the topographic difference between precipitation input and runoff output as available potential energy, which is due to an influx of free energy from precipitation. Potential energy of infiltration excess water at the hillslope surface is converted into kinetic energy of overland

135 flow, and kinetic energy is dissipated into heat (Figure 1). In this two-box scheme we consider only the energies of water flow. In order to highlight spatial distribution of energy we subdivide the hillslope into segments along the horizontal flow path $\mathrm{x}$ (Figure 2) with given width $\mathrm{b}(\mathrm{x})$ and express fluxes in $\mathrm{W} \mathrm{m}^{-1}$. We can thus write the energy balance equations for any segment $\mathrm{x}$ of the hillslope OTS:

$$
\begin{gathered}
\frac{d E_{f}^{p e}(x)}{d t}=J_{f, \text { in }}^{p e}(x)-J_{f, \text { out }}^{p e}(x)+J_{P, \text { in }}^{p e}(x)-J_{\text {Inf }, \text { out }}^{p e}(x)-P_{f}(x) \\
\frac{d E_{f}^{k e}(x)}{d t}=P_{f}(x)-D_{f}(x)+J_{f, \text { in }}^{k e}(x)-J_{f, \text { out }}^{k e}(x)
\end{gathered}
$$

Fluxes with superscript "pe" relate to potential energy and fluxes with superscript "ke" relate to kinetic energy. Subscript "f" relates to surface runon and runoff, subscript "inf" to infiltration and subscript "P" to precipitation (see table 1). Eq. (2) accounts for all changes of potential energy of runoff $E_{f}^{p e}$ and Eq. (3) is the energy balance of kinetic energy of water $E_{f}^{k e}$. We further define $J_{f, \text { net }}^{p e}\left[W m^{-1}\right], J_{f, \text { net }}^{k e}\left[W m^{-1}\right], J_{P e f f}^{p e}\left[W m^{-1}\right]$ (Eq. (4) to (6)), as the net boundary energy fluxes which surface $145 \operatorname{runon}\left(J_{f, i n}^{p e}\left[W m^{-1}\right], J_{f, \text { in }}^{k e}\left[W m^{-1}\right]\right)$, precipitation and infiltration $\left(J_{P, \text { in }}^{p e}\left[W m^{-1}\right], J_{i n f, o u t}^{p e}\left[W m^{-1}\right]\right)$, as well as surface runoff $\left(J_{f, \text { out }}^{p e}\left[W m^{-1}\right], J_{f, \text { out }}^{k e}\left[W m^{-1}\right]\right)$, set on the system. $P_{f}\left[W m^{-1}\right]$ is the transfer from potential to kinetic energy and $D_{f}\left[W^{-1}\right]$ is the remaining energy, which has not been conserved as potential or kinetic energy of the water flow and leaves 
the system. $D_{f}$ is more than dissipation by friction, as it includes any other type of energy which was gained from the initial water flow energy gradient such as work needed for sediment transport. Dissipation means free energy that is lost as heat, kinetic energy transfer to the sediment is not dissipated, as it creates macroscopic motion. In the following, we neglect the kinetic energy transfer to sediments (and other mass) and refer to $\mathrm{D}_{\mathrm{f}}$ simply as the dissipation for all energy that is not conserved in the flow of water. As generally accepted, we assume that infiltration and precipitation act mostly on the potential energy and neglect their influences on kinetic energy. The net energy fluxes are thereby defined as:

$$
\begin{gathered}
J_{f, \text { in }}^{p e}(x)-J_{f, \text { out }}^{p e}(x)=J_{f, \text { net }}^{p e}(x) \\
J_{P, \text { in }}^{p e}(x)-J_{\text {inf }, \text { out }}^{p e}(x)=J_{\text {Peff }}^{p e}(x) \\
J_{f, \text { in }}^{k e}(x)-J_{f, \text { out }}^{k e}(x)=J_{f, \text { net }}^{k e}(x)
\end{gathered}
$$

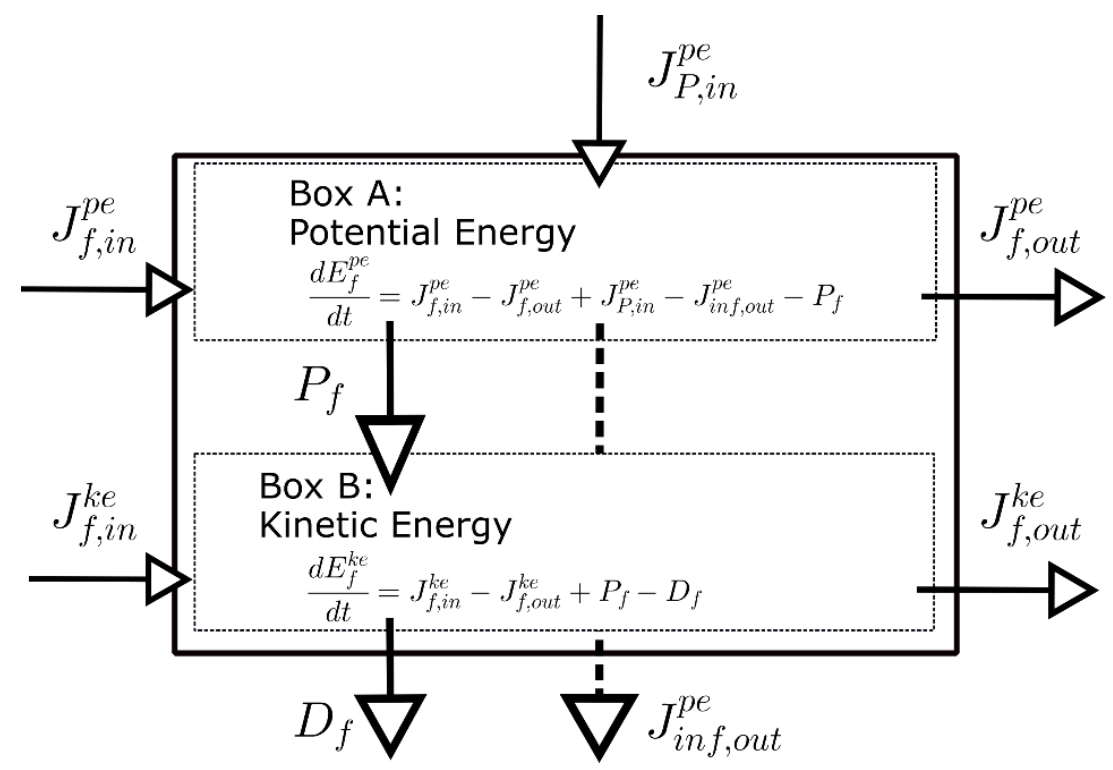

Figure 1: The hillslope surface runoff as a two box open thermodynamic system

With Eq. (2) to (6) the total free energy balance is:

$$
\frac{d E_{f}^{p e}(x, t)}{d t}+\frac{d E_{f}^{k e}(x, t)}{d t}=J_{f, n e t}^{p e}(x, t)+J_{f, n e t}^{k e}(x, t)+J_{P e f f, n e t}^{p e}(x, t)-D_{f}(x, t)
$$


160 This means that the change in total free energy of the system is the sum of the differences in the net boundary energy fluxes minus dissipation. In the case of steady state $\left(\frac{d E_{f}^{p e}(x, t)}{d t}=\frac{d E_{f}^{k e}(x, t)}{d t}=0\right)$, dissipation $\mathrm{D}_{\mathrm{f}}$ can be maintained if the net boundary fluxes are non-zero. It should be noted that within the balance of total free energy the net boundary fluxes of a kind may become negative, therefore seemingly the system exports more energy than is imported. What might seem like a violation of conservations is just the result of the transient mass balance. Downslope water movement does not just imply a reduction in

165 its geopotential, but also that additional rainfall is added on this way. In such a distributed mass accumulating system, it is therefore possible that the gain in mass per unit length adds more potential energy than is converted into kinetic energy. From a more traditional Navier-Stokes momentum balance centered point of view this corresponds to an increase in momentum while the velocity is constant. Considering the momentum balance in Eq. (8) (modified after Kleidon et al., 2013), we can see that the accelerating force per unit length $F_{a c c}[N]$ depends on total mass $\mathrm{m}[\mathrm{kg}]$, whereas the counteracting drag force of turbulent flow $F_{d}[N]$ is direct proportional to the square of the velocity v $\left[\mathrm{m} \mathrm{s}^{-1}\right]$. The total output of momentum flux $J_{\text {out }}^{p}[\mathrm{~N}]$ however, is dependent on both mass and velocity therefore facilitating momentum dynamics where the change of momentum is due to a mass increase without change in flow velocity $(\mathrm{dv} / \mathrm{dt}=0)$.

$$
\frac{d(m * v)}{d t}=F_{a c c}(m)-F_{d}\left(v^{2}\right)-J_{o u t}^{p}(m, v)=\frac{d m}{d t} * v+\frac{d v}{d t} * m
$$

\subsection{Steady state spatially distributed energy of overland flow}

\subsubsection{Energy flow between thermodynamic sub systems}

175 In order to analyze the distribution of energy conversion processes in space we speak of open thermodynamic subsystems $\left(\right.$ OTS $\left._{\text {sub }}\right)$ that are assumed to be in steady state as shown in Fig. 2. 


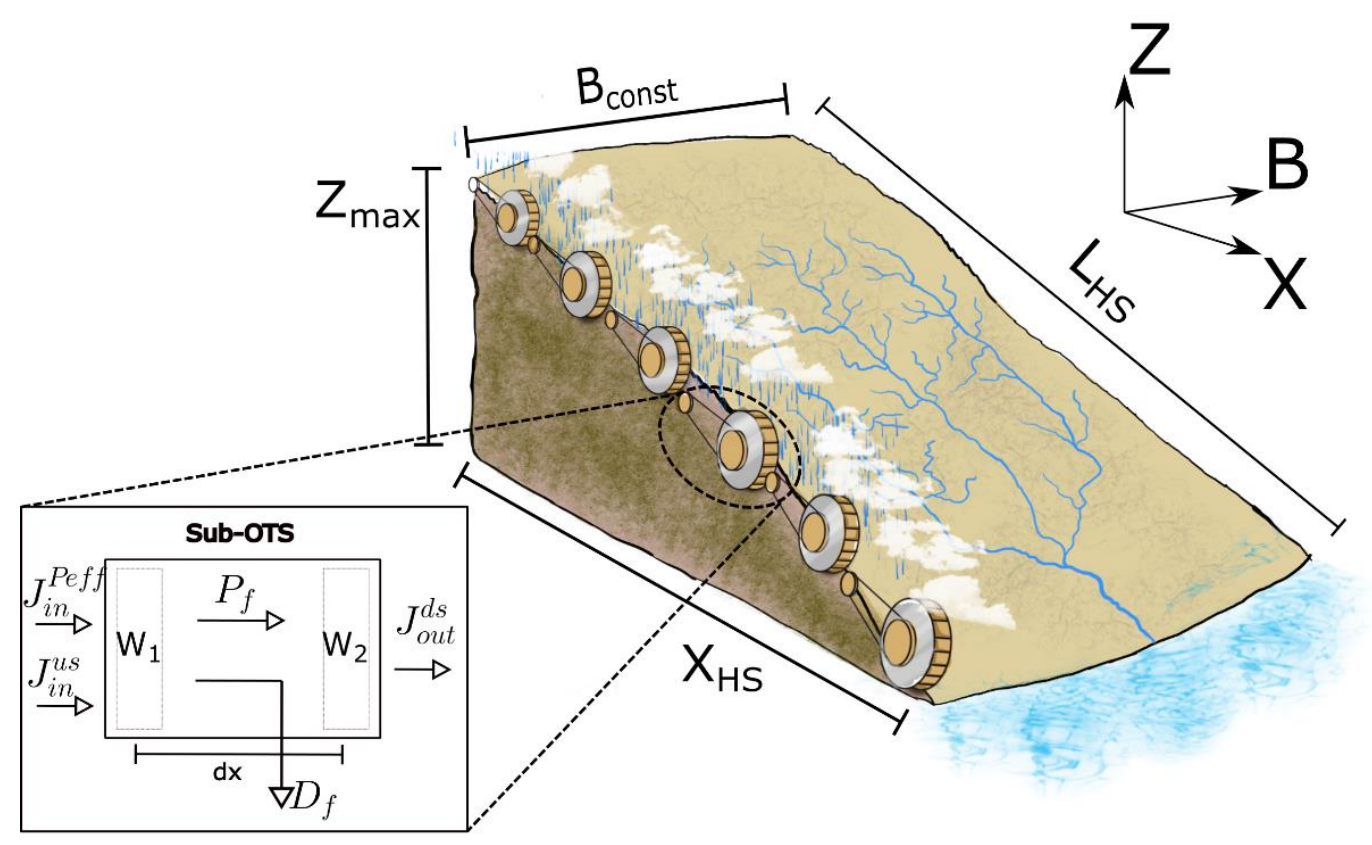

Figure 2: Hillslope open thermodynamic system with spatial division into sub-OTS and energy flows from upstream and downstream $\left(J_{i n}^{u s}=J_{i n}^{p e}+J_{i n}^{k e}\right.$ and $\left.J_{o u t}^{d s}=J_{o u t}^{p e}+J_{o u t}^{k e}\right)$ as well as free energy reservoirs $\mathrm{W}_{1}$ and $\mathrm{W}_{2}$

For each $O T S_{\text {sub }}$ we apply Eq. (7) where potential and kinetic energy of the system do not change with time, so that:

$$
0=J_{f, n e t}^{p e}(x)+J_{f, n e t}^{k e}(x)+J_{P e f f}^{p e}(x)-D_{f}(x)
$$

For potential energy conversion (Eq. (2)) we obtain:

$$
\begin{gathered}
\frac{d E_{f}^{\mathrm{pe}}(x)}{d t}=0=J_{f, n e t}^{p e}(x)+J_{P e f f}^{p e}(x)-P_{f}(x) \\
J_{f, n e t}^{p e}(x)+J_{P e f f}^{p e}(x)=P_{f}(x)
\end{gathered}
$$

While kinetic energy conversion (Eq. (3)) is as follows:

$$
\begin{gathered}
\frac{d E_{f}^{k e}(x)}{d t}=0=P_{f}(x)-D_{f}(x)+J_{f, \text { net }}^{k e}(x) \\
P_{f}(x)=D_{f}(x)-J_{f, \text { net }}^{k e}(x)
\end{gathered}
$$

180 To relate the spatial distribution of energy with energy fluxes we recall that the downslope mass flux $\overrightarrow{\boldsymbol{v}} * \mathrm{~m}$ is associated with downslope flux of kinetic and potential energy. The net fluxes correspond to the divergence of the kinetic and potential energy flow. $J_{f}^{p e / k e}$ [watt] is here defined as the advective energy flux, which is the product of specific energy $\mathrm{E}_{\mathrm{sp}}\left[\mathrm{joule} \mathrm{kg}^{-1}\right.$ ] and flow rate $\rho * Q\left[\mathrm{~kg} \mathrm{~s}^{-1}\right]$ (Eq. (13)). As per definition of Eq. (4) to (6), $\mathrm{J}_{\mathrm{f}, \text { net }}$ is positive for a decrease of energy flux over the control volume and therefore has the opposite sign to change in energy: 


$$
\begin{gathered}
J_{f, n e t}^{p e / k e}=-\operatorname{div}\left(J_{f}^{p e / k e}(x)\right) \\
J_{f}^{p e}=E_{s p}^{p e}(x) * Q(x)=g * h(x) * \rho * Q(x) \\
J_{f}^{k e}=E_{s p}^{k e}(x) * Q(x)=\frac{v(x)^{2}}{2} * \rho * Q(x) \\
J_{P e f f}^{p e}(x)=\rho * P_{e f f}(x) * g * h(x) * b(x)
\end{gathered}
$$

185

Inserting the expressions for specific potential and kinetic energy (Eq. (13)) into Eq. (12), we can apply the derived energy balance (Eq. (10)) for the calculation of power to create kinetic flow energy and Eq. (11) for the dissipation of flow energy per unit length in $\left[\mathrm{W} \mathrm{m}^{-1}\right]$ :

$$
\begin{aligned}
& P_{f}(x)=J_{f, n e t}^{p e}(x)+J_{P e f f}^{p e}(x) \\
& =\rho * g *\left(-\frac{d Q(x)}{d x} * h(x)-\frac{d h(x)}{d x} * Q(x)+P_{e f f}(x) * h(x) * b(x)\right) \\
& \begin{aligned}
D_{f}(x)=P_{f}(x) & +J_{f, n e t}^{k e}(x) \\
& =\rho * g *\left(-\frac{d Q(x)}{d x} * h(x)-\frac{d h(x)}{d x} * Q(x)+P_{e f f}(x) * h(x) * b(x)\right) \\
& -\frac{1}{2} * \rho *\left(\frac{d Q(x)}{d x} * v(x)^{2}+2 * v(x) * \frac{d v(x)}{d x} * Q(x)\right)
\end{aligned}
\end{aligned}
$$

The energy, which is dissipated per unit length (that is per OTS $S_{s u b}$, along the horizontal flow path $\mathrm{x}$ ), depends on the net potential plus the net kinetic energy flow plus the additional energy input per time through precipitation. With the assumption that change of velocity in space is close to zero and $\frac{d Q(x)}{d x}=P_{e f f} * b(x)$ Eq. (16) becomes:

$$
D_{f}(x)=P_{e f f} * \rho * g * b(x) *\left(-h(x)-\frac{v_{\text {const }}^{2}}{2 * g}\right)-Q(x) * \rho * g * \frac{d h(x)}{d x}
$$

Eq. (17a) is the representation of a system where the change in velocity in space is very small in comparison to the geopotential gradient and can be neglected. We can also see that the first term scales with $\mathrm{P}_{\text {eff }}$ and the second with $\mathrm{Q}$. With precipitation usually decreasing and discharge increasing in downstream direction, there will be a flow path length where we can reduce Eq. (17a) to its second term $\left(P_{e f f}(x) \ll Q(x)\right)$ :

$$
D_{f}(x)=-Q(x) * \rho * g * \frac{d h(x)}{d x}
$$


This could be the case for a larger stream and explain how systems with small variation of mass minimize energy dissipation by flattening of their geopotential gradients $\left(\frac{d h(x)}{d x}\right.$ approaches very small values). As more and more mass accumulates along the flow path, dissipation of discharge power is less controlled by changes in velocity or mass. This results in an increasingly flattened geopotential gradient and therefore a negative exponential distribution of geopotential (Leopold and Langbein, 1962).

\subsubsection{Power dynamics of a sequence of sub-OTS}

For each sub-OTS along the hillslope we observe a net potential, a net kinetic energy flux and an effective rainfall flux $J_{f, n e t}^{p e}, J_{f, n e t}^{k e}$ and $J_{P e f f}^{p e}$. These fluxes define the boundary conditions of the subsystems, whereas the change in these fluxes along the hillslope are the result of work performed by the sub-OTS. In order to examine the changes in energy along a flow path we need to relate discharge with mass (flow depth). As we assume that the change of flow depth $H$ is much smaller than the change of water level $\left(\frac{d H}{d x} \ll \frac{d h}{d x}\right)$, we compute $H$ with the Manning-Strickler equation (Eq. (18)). For sheet flow, the hydraulic radius is approximated as the water depth.

$$
\begin{gathered}
H(x)=\left(n * \frac{Q(x)}{b(x) * \sqrt{S}}\right)^{\frac{3}{5}} \\
v(x)=n^{-\frac{3}{5}} *\left(\frac{Q(x)}{b(x)}\right)^{\frac{2}{5}} * S^{\frac{3}{10}}
\end{gathered}
$$

Where $n$ is the Manning coefficient in $\mathrm{s} \mathrm{m}^{-1 / 3}$. Eq. (19) is another form of Eq. (18) that estimates the distribution of velocity along the horizontal flow path for the hillslope-OTS. We approximate energy gradients with topographic slope S, which we consider appropriate as long as change in geopotential is much larger than change in water depth.

Eq. (18) and (19) are sensitive to hillslope topography $\mathrm{z}(\mathrm{x}), \mathrm{b}(\mathrm{x})$ and precipitation $\mathrm{I}(\mathrm{x})$. Depending on the distribution of width, length and geopotential, energy conversion processes will show spatial and temporal differences. For the same hillslope surface area, a converging width distribution leads to higher discharge at shorter flow path distances than diverging widths. Similarly, linearly distributed morphology provides different geopotential gradients in comparison to e.g. an exponentially sloped terrain (compare Fig. 3 and Fig. 4). Even if we consider rainfall as spatially homogeneous, its intensity will influence energy conversions. In the following section, we analyse these sensitivities and deduce patterns of energy conversion dynamics of surface runoff. Finally, we calculate maximum energy conversion rates, distributed in space but also of the whole hillslope. The integral in space over the net boundary fluxes of energy in time $\left[\mathrm{W} \mathrm{m}^{-1}\right]$ is the total energy in time $[\mathrm{W}]$ that converts into some other form of energy (Eq. (20)).

$$
P_{f}(x)=\int_{0}^{x} P_{f}(x) d x
$$




$$
\begin{gathered}
D(x)=\int_{0}^{x} D_{f}(x) d x \\
J^{k e}(x)=\int_{0}^{x} J_{f, n e t}^{k e}(x) d x
\end{gathered}
$$

\section{Applications}

\subsection{Distributed energy dynamics as function of rainfall, hillslope form and width}

In this section, we define different examples of hillslope configurations and effective rainfall forcing. We distinguish four typical hillslope forms, characterized by either a linear, sinusoidal, exponential or a negative exponential geopotential function along a representative flow path $\mathrm{x}($ Fig. $4(\mathrm{a}))$ :

$$
\begin{aligned}
& z_{\text {lin }}(x)=-\frac{z_{\text {max }}}{x_{H S}} * x+z_{\text {max }} \\
& z_{\text {sin }}(x)=\frac{z_{\text {max }}}{2} * \cos \left(\frac{x}{x_{H S}} * \pi\right)+\frac{z_{\text {max }}}{2} \\
& z_{\text {exp }}(x)=e^{-x * 2 * k} * z_{\text {lin }}(x) \\
& z_{\text {neg }}(x)=-e^{x * k} *-z_{\text {lin }}(x)
\end{aligned}
$$

225 All hillslope forms start at $\mathrm{Z}_{\max }$, the maximum specific geopotential in $\mathrm{m}^{2} \mathrm{~s}^{-2}$, and end at zero, depleting all available geopotential gradients. In our examples, we assumed $\mathrm{z}_{\max }$ as the specific geopotential of $10 \mathrm{~m}$ altitude multiplied by the gravity of the earth of $9.81 \mathrm{~m}^{2} \mathrm{~s}^{-2}$, and a projected hillslope length $\mathrm{X}_{\mathrm{HS}}$ of 100 meters (see Fig. 4(a)). $\mathrm{K}$ is a smoothing factor for the exponential functions and equals $0.01 \mathrm{~m}^{-1}$. Four simple forms have been chosen as they represent the different geomorphological stages of a hillslope under erosion in time, starting with $\mathrm{z}_{\text {neg }}$ as the youngest formation (largest gradients towards the end) and ending with $\mathrm{z}_{\mathrm{exp}}$ and $\mathrm{z}_{\mathrm{sin}}$ as older formations (smaller gradients towards the end).

These different forms we then combine with three different width distributions, which are either constant, converging or diverging. In our analysis we keep the projected area constant at $5000 \mathrm{~m}^{2}$ for all configurations, which results in an equal total runoff from all hillslope forms for a given effective rainfall intensity. Fig. 3 shows the three types of width distributions considered in this study for linearly sloped terrain. Finally, we computed steady state runoff for effective rainfall intensities of

$2355-, 10-, 20$ - and 50-mm hr-1 either without runon $\left(\mathrm{Q}_{0}=0\right)$ or with $20 \mathrm{~kg} \mathrm{~s}^{-1}$ runon $\left(\mathrm{Q}_{0}=0.02 \mathrm{~m}^{3} \mathrm{~s}^{-1}\right)$, which is roughly a quarter of the maximum accumulated runoff at $50 \mathrm{~mm} \mathrm{hr}^{-1}$ rainfall (compare Fig. 4, panels (c) and (d)). It should be noted that we considered one case with no rainfall and runon only $\left(\mathrm{I}=0 ; \mathrm{Q}_{0}>0\right)$. We included this scenario to highlight the differences between runon without rainfall accumulation and runoff with rainfall accumulation when calculating spatial energy dynamics. The differently dotted lines in Fig. 4, panels (b), (c) and (d) represent the three hillslope width distributions and show their influence

240 on runoff accumulation. Nevertheless, the total runoff at the end of the hillslope is independent of width distribution as the projected area remains equal for all hillslope forms. 


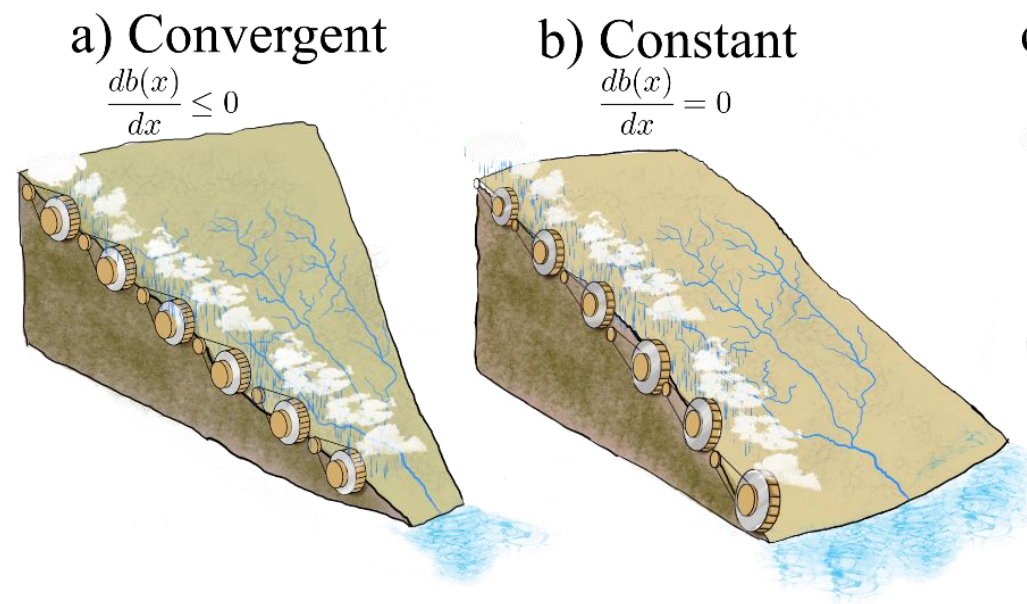

c) Divergent

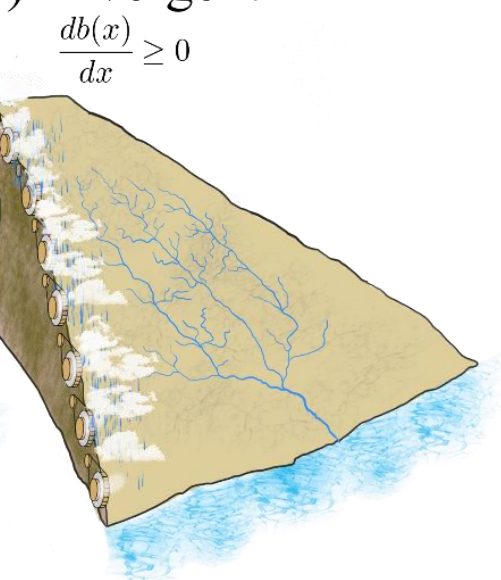

Figure 3: Linear hillslope OTS with different functions of hillslope width

A)

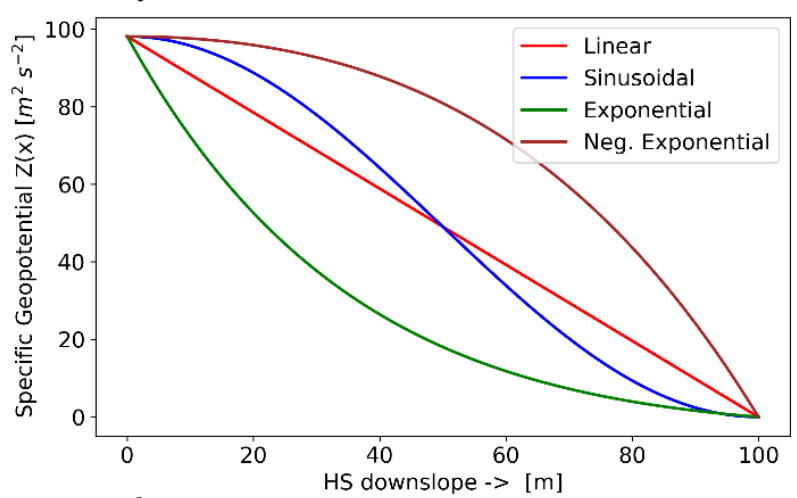

C)

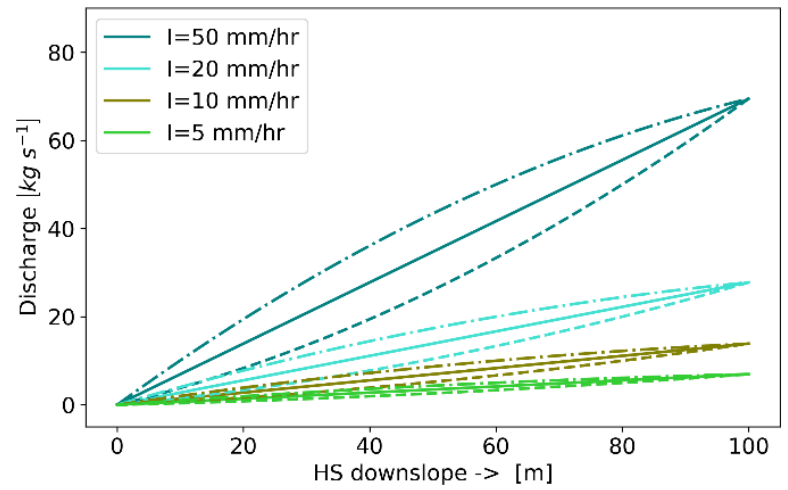

B)

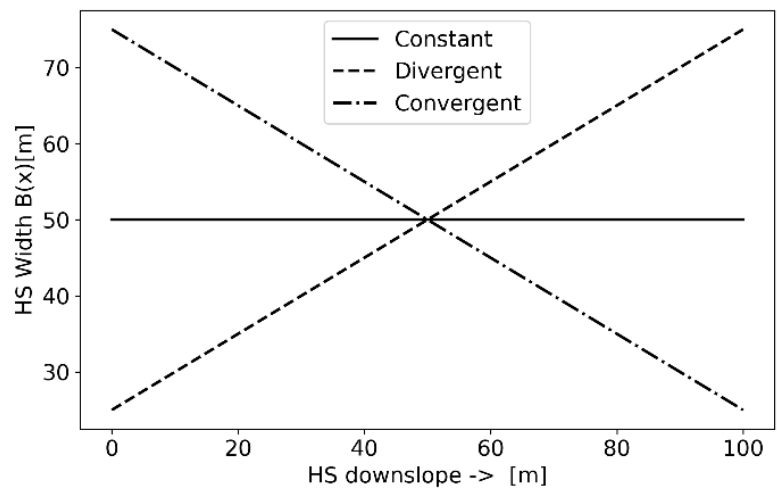

D)

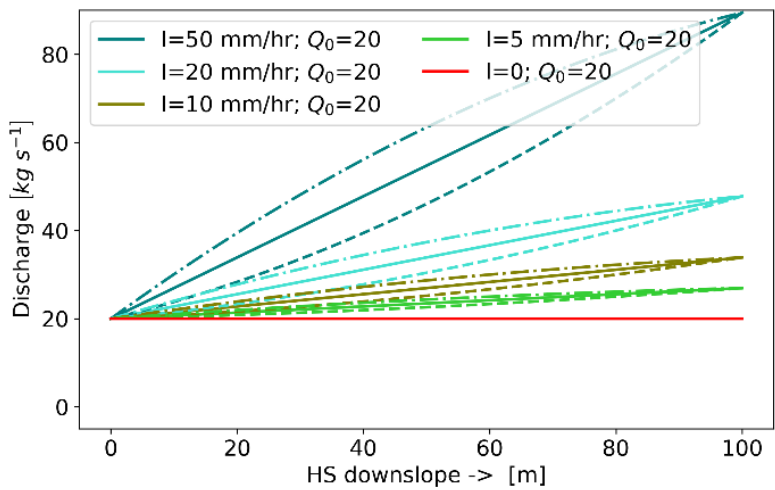

Figure 4: Topography and width of the different hillslopes (panels a and b), resulting steady state discharge along the hillslope for the case of no and constant runon of $20 \mathrm{~kg} \mathrm{~s}^{-1}$ (panels $\mathrm{c}$ and d). The line types in panels $\mathrm{c}$ and $\mathrm{d}$ correspond to the width functions in panel $b$ 
For all combinations of runoff accumulation and hillslope topography, we computed the steady state spatial distribution of water mass and flow velocity using Eq. (18) and Eq. (19) and a Manning-Strickler value of $0.1 \mathrm{~s} \mathrm{~m}^{-1 / 3}$. We then computed fluxes of potential flow energy $E_{f}^{p e}$, kinetic flow energy $E_{f}^{k e}$, effective rainfall and power $\mathrm{P}_{\mathrm{f}}$ to convert potential to kinetic energy per unit flow length with Eq. (12) to Eq. (15).

\subsection{The role of rills: A first order assessment}

The previous applications are meant to shed light on how different hillslope forms, width and rainfall forcing affect steady state energy conversions. However, from Eq. (16) we can see that loss of energy per unit length also depends on flow velocity. In a mass accumulating system, average flow velocity increases through accumulation and acceleration of mass. The latter is associated with dissipation of the flow energy and the efficiency of energy conversion processes. For discharge in steady state, average flow velocity can only increase if friction per discharge decreases. Although we want to emphasize that friction itself is a more complicated matter as it conveys a multitude of micro- and macroscopic processes, for simplicity we make use of the standard definition of Manning-Strickler (Eq. (18)), with resistance to flow consisting of geometry (hydraulic radius) and surface roughness (Manning-Strickler coefficient) (for a given energy gradient) only. Assuming that surface roughness is fixed, we can then relate the geometry of the surface to efficiency of energy conversion of surface runoff. Rills are of special interest to us, as they are the direct result of surface adaptation to high Hortonian surface runoff rates (Berger et al., 2010). In the following, we intend to derive a first order assessment of the transition from sheet- to rill flow. In a first step, we consider a cross section with width $\mathrm{b}$ of $30 \mathrm{~m}$ and a given discharge $\mathrm{Q}_{\mathrm{s}}$ of $0.1 \mathrm{~m}^{3} \mathrm{~s}^{-1}$ that is driven downslope by an energy gradient $\mathrm{I}_{\mathrm{e}}$ of $0.1 \mathrm{~m} \mathrm{~m}^{-1}$ (Figure 5 (a)). In accordance with the theory, we imagine a sheet of water with height $\mathrm{h}_{\mathrm{s}}$ of roughly $0.016 \mathrm{~m}$ (Eq. (18)) or total sheet flow area $A_{S}$ of approximately $0.5 \mathrm{~m}^{2}$ flowing downslope.

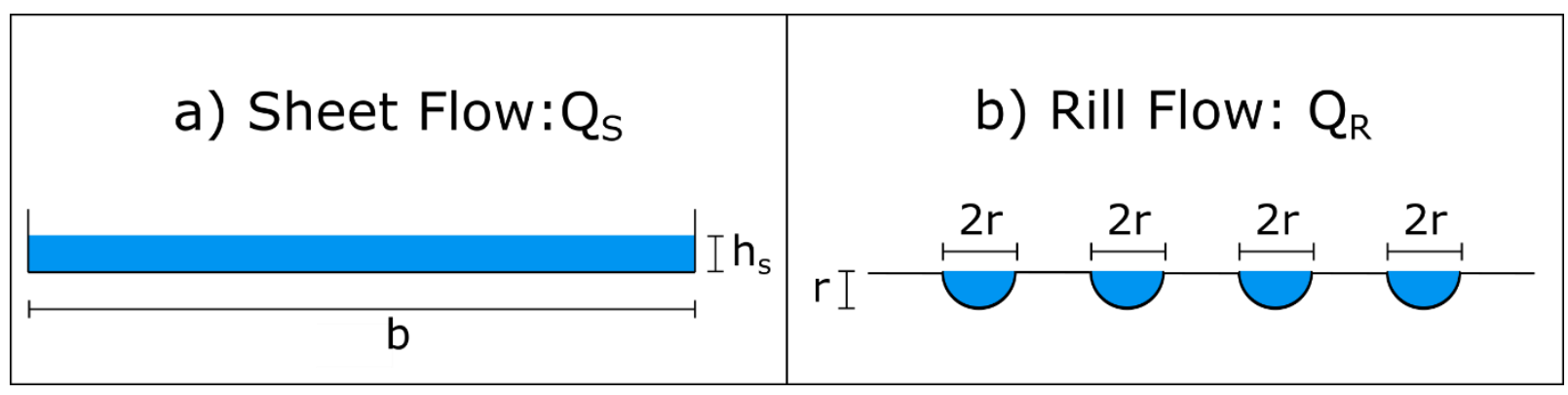

Figure 5: a) Sketch of cross section with sheet flow $Q_{S}$ and b) Rill flow, each of $m$ channels carries $Q_{\mathrm{R}}$ at rim full conditions.

In a second step we simulate the formation of rills by inserting $m$ channels into the surface of the cross section (Figure 5 (b)).

Each channel is idealized by a half circled cross section with radius $r$ and area $A_{R}=\frac{r^{2} * \pi}{2}$ and carries a flow of $Q_{R}=\frac{Q_{S}}{m}$. We assume each channel to be filled to the rim with water, exploiting the maximum rill conductance. With $v=\frac{Q}{A}$, the ratio of the average velocity of sheet flow $v_{S}$ and rill flow $v_{R}$ as a function of rill number $m$ is: 


$$
\frac{v_{R}}{v_{S}}=m * \frac{A_{S}}{A_{R}}=\frac{2 * b * h_{s}}{m * r^{2} * \pi}
$$

Further using Eq. (19) to replace the velocity terms:

$$
\frac{R_{R}}{R_{S}}=\left(\frac{2 * b * h_{s}}{m * r^{2} * \pi}\right)^{\frac{3}{2}}
$$

\subsection{Stream power and erosional force}

275 Finally, yet importantly, we relate our theory to the theory by Horton (1945) about stream power and erosional force. This is straightforward, as physical work relates to force times displacement, which implies that power is the product of the driving force and flow velocity. While the accelerating downslope force relates to the creation of kinetic energy and thus power $\mathrm{P}_{\mathrm{f}}$, the counteracting friction force relates to its dissipation. The steady state spatial distribution of power relates hence to the distribution of forces acting on the bed material as well as on the water and suspended sediment particles along the hillslope. Based on these insights Horton (1945) developed a theory of maximum erosion as water accumulates downslope. By combining the DuBoys equation with Manning's law he expressed the energy which is liberated per unit time and unit flow area $\left[\mathrm{W} \mathrm{m} \mathrm{m}^{-2}\right]$ as

$$
P^{H o r t o n}(x)=\rho * g * D(x) * v_{T}(x)=\rho * g *\left(n * \frac{Q(x)}{b(x)}\right)^{\frac{3}{5}} * v * \frac{\sin \alpha}{\tan ^{0.3} \alpha}
$$

Where $\alpha$ is the degree slope angle and $n$ the Manning-Strickler coefficient in $\left[\mathrm{s} \mathrm{m}^{-1 / 3}\right]$. The force per unit area has the units $[\mathrm{kg}$ $\left.\mathrm{m}^{-1} \mathrm{~s}^{-2}\right]$. Horton's equation is based on the assumption that energy that is dissipated per unit length can be deducted from the steady state formulation for loss of potential energy, neglecting changes in kinetic energy. Horton claimed that his formula led to a maximum divergence of energy flow (or maximum erosion force) at the maximum value of the term $f_{s}=\frac{\sin \alpha}{\tan ^{0.3} \alpha}$, which he termed slope function. We believe that Horton's initial formulation (Eq. (24), compare Horton, 1945) has to be adjusted for variation of the flow area on which the energy conversion processes act (forces act on $d_{\text {OTS }}$ not on $d x$, compare Fig. 6) with variation of the slope angle. Therefore, for larger values of $\alpha$, Eq. (24) has to be adjusted by a factor of $\cos ^{-1} \alpha$ which ultimately leads to the well-known equation of stream power per flow area [W $\left.\mathrm{m}^{-2}\right]$ in steady state (Bagnold, 1966):

$$
P^{\text {Bangold }}(x)=\rho * g * D(x) * v(x) * \frac{\sin \alpha}{\cos \alpha}=\rho * g * \frac{Q(x)}{b(x)} * \tan \alpha
$$

Eq. (25 a) divided by flow velocity leads to Eq. ( 25 b), the depth-slope product (Bangold, 1966) and is still used today for the calculation of bed shear stress $\tau_{b}$ in $\mathrm{N} \mathrm{m}^{-2}=\mathrm{kg} \mathrm{m}^{-1} \mathrm{~s}^{-2}$.

$$
F_{\text {erosion }}(x)=\frac{P^{\text {Bangold }}(x)}{v(x)}=\rho * g * D(x) * S
$$




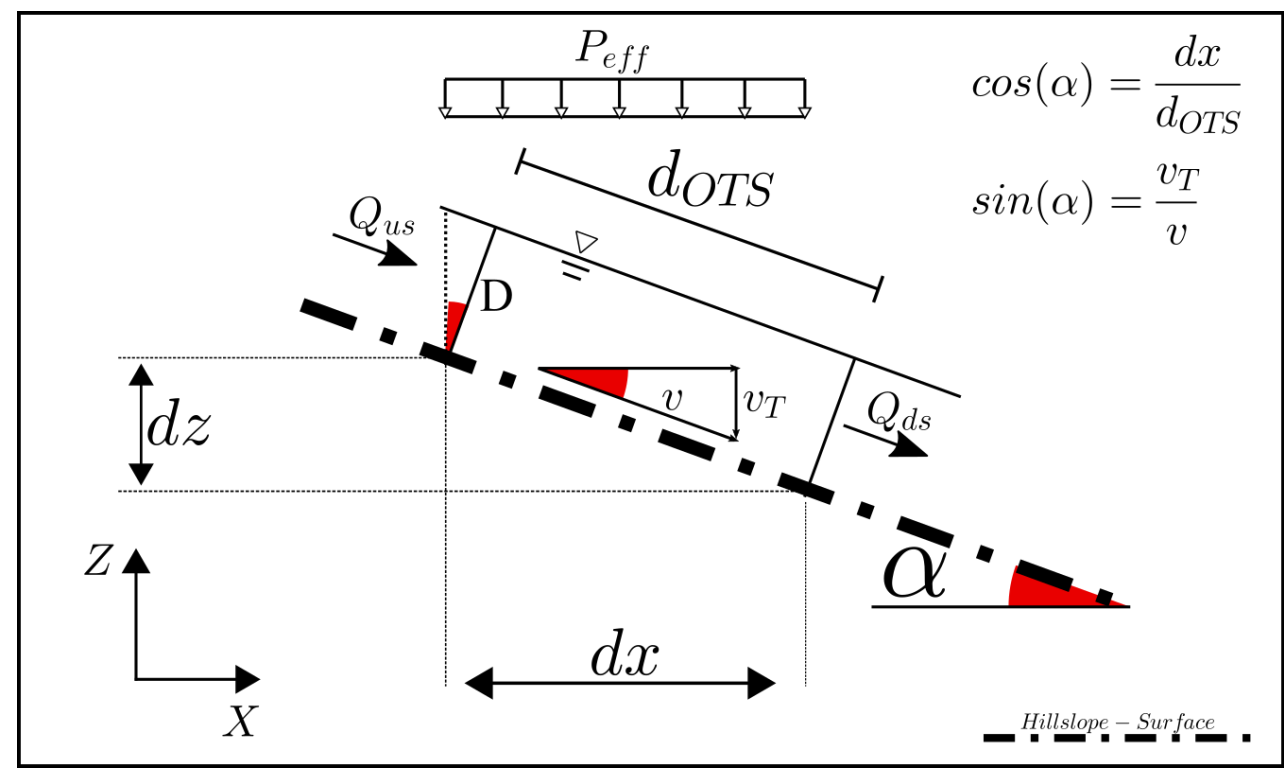

Figure 6: Flow accumulation within a sub-OTS and relation of mean flow velocity $v(x)$ and flow area $d_{O T S}$ to slope angle $\alpha$

295 Comparing Eq. (25 b) with our formulation of dissipation (Eq. (16)) we can see that this traditional equation is a reduced version of the general expression of stream power. Assuming steady state with no change in velocity and mass Eq. (16) becomes Eq. ( 25 b) or the equivalent Eq. (17 b). Here we provide therefore a full description of stream power of surface runoff and can distinguish four cases (see Table 2).

Table 2: Four cases of dissipation of surface runoff energy

\begin{tabular}{lll}
\hline & Assumption & Dissipation \\
\hline 1. & Full equation & Eq. (16) \\
\hline 2. & Hortonian stream power: $\frac{d Q(x)}{d x}=0$ and $\frac{d v(x)}{d x}=0$ & Eq. (25 a); Eq. (17 b) \\
\hline 3. & $\frac{d Q(x)}{d x}=0$ & $D_{f}(x)=\rho * g *\left(-\frac{d h(x)}{d x} * Q_{\text {const }}-\frac{1}{g} * v(x) * \frac{d v(x)}{d x} * Q_{\text {const }}\right)$ \\
\hline 4. & $\frac{d v(x)}{d x}=0$ & $D_{f}(x)=\rho * g *\left(-\frac{d Q(x)}{d x} * \frac{v_{\text {const }}^{2}}{2 * g}-\frac{d h(x)}{d x} * Q(x)\right)$ \\
\hline
\end{tabular}

In the following, we first computed for a linear hillslope with varying slope angles $P_{f}, J_{f, n e t}^{k e}$ and $D_{f}$ with the full equation (Eq. (16)) and analyzed results for maximum values. Secondly, we computed $P_{f}, J_{f, n e t}^{k e}$ and $D_{f}$ for a single linear hillslope but for all four cases (Table 2) and compared the results to the standard computation of stream power and erosional force after Horton and Bangold (Eq. (25 a) and Eq. (25 b)). We finally integrated the spatially distributed energy fluxes over the whole hillslope for all slope angles with Eq. (20) and compared the results with the analytical solution (Appendix A). 


\section{Results}

\subsection{Spatial distribution of energy and power}

\subsubsection{Spatial maxima of potential energy}

Generally, we found that the trade-off of downslope mass accumulation and declining geopotential leads to a distinct potential energy maximum, which has a clear dependence on the slope form, width function and strength of rainfall forcing (Figure 7). This implies that the hillslope can be sub-divided into three classes of spatial energy dynamics:

$$
\begin{aligned}
& \text { 1) } \frac{d E_{f}^{p e}(x)}{d x}>0 \\
& \text { 2) } \frac{d E_{f}^{p e}(x)}{d x}=0 \\
& \text { 3) } \frac{d E_{f}^{p e}(x)}{d x}<0
\end{aligned}
$$

315 Within the first interval potential energy flux increases along the flow path, as the additional mass from rainfall adds more energy to the sub-OTS than flows out. At a certain distance (interval 2), energy outflow equals energy input through precipitation plus upstream inflow and we observe an energetic maximum. Within the third interval, energy outflow is continuously larger than energy inflow, effectively depleting the accumulated geopotential of interval 1. Overall, we observe for a mass accumulating hillslope OTS from top to foot that net potential energy first accumulates, at some distance peaks and then decreases. At the end of the hillslope all available potential energy has completely converted into some other kind of energy.
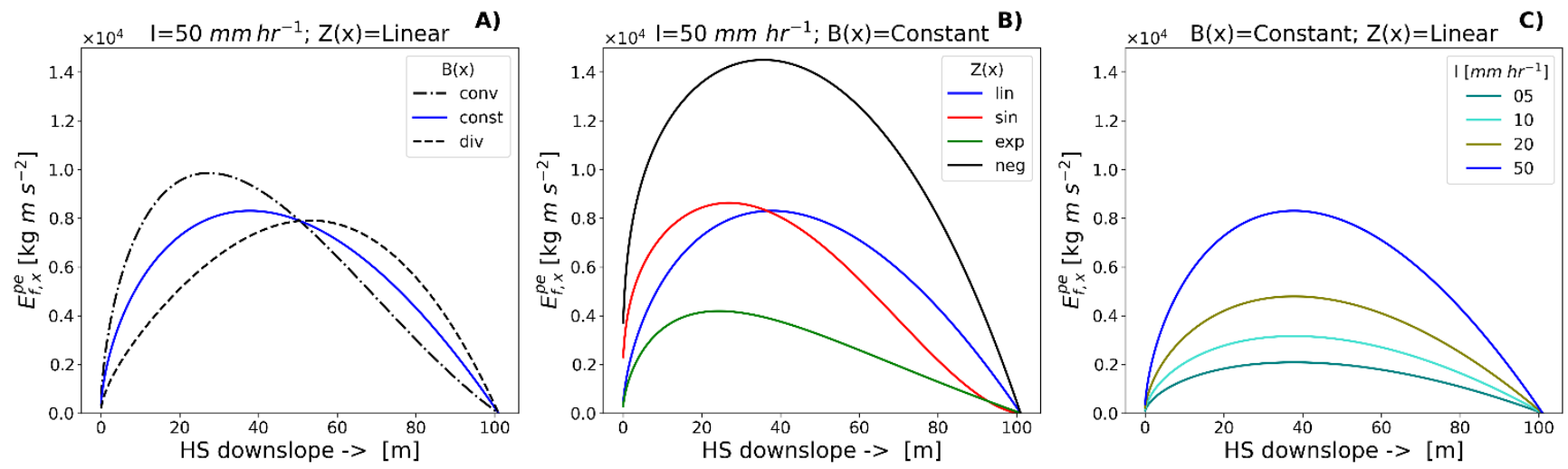

Figure 7: Distribution of potential energy $E_{f}^{p e}$ per unit length in [Joule $\left.\mathbf{m}^{-1}\right]$ as a function of a) hillslope width b) geopotential distribution (form) and c) rainfall intensity $I$

Figure 7 (a) shows that the location of the energetic maximum moves upslope when changing the width function from divergent (div), over parallel (const) to convergent (conv). The magnitude of the absolute value of the maximum increases in a similar fashion. The distribution of geopotential from top to bottom clearly influences the location and size of maxima (Figure 
7 panel (b)). Interestingly a hillslope with a negative exponential form, which is morphologically the youngest, has by far the

largest potential energy maximum and therefore highest geopotential difference with the hillslope end. Larger differences mean more available potential energy to perform work within the specified hillslope distance, which might result in enhanced erosion in comparison to e.g. sinusoidal or exponential hillslope forms. In line with this theory about morphological ages is also the growth of energy gradients from exponential and sinusoidal to negative exponential (old, smaller gradients to young, larger gradients). Similarly, rainfall intensity can increase or decrease absolute maxima as well as gradients (panel c)). Although larger rainfall intensities have no influence on the downslope location of the maxima, they do influence the spatial distribution of energetic gradients resulting in more power during the energy conversion processes. We state that the distribution of potential energy in space as a function of hillslope width, form and rainfall intensity seems to go hand in hand with the timeline of erosional processes.

\subsubsection{Runoff vs. runon systems}

340 We now separate cases that accumulate runoff in downslope direction from cases with runon and transitory states (compare Figure 4, panels (c) and (d)). In Figure 8, panel (a) we plotted $E_{f}^{p e}(x)$ of all considered geopotential distributions $\mathrm{z}(\mathrm{x})$ with a constant width for a rainfall intensity of $50 \mathrm{~mm} \mathrm{hr}^{-1}$ without runon $\left(\mathrm{Q}_{0}=0\right)$. Contrarily, panel c) shows the potential energy distribution for a runon-only system without rainfall ( $\mathrm{I}=0)$ and $\mathrm{Q}_{0}$ of $20 \mathrm{~kg} \mathrm{~s}^{-1}$. Panel b) represents the transition from a runoffonly to a runon-only system with a rainfall of $50 \mathrm{~mm} \mathrm{hr}^{-1}$ and runon of $20 \mathrm{~kg} \mathrm{~s}^{-1}$.
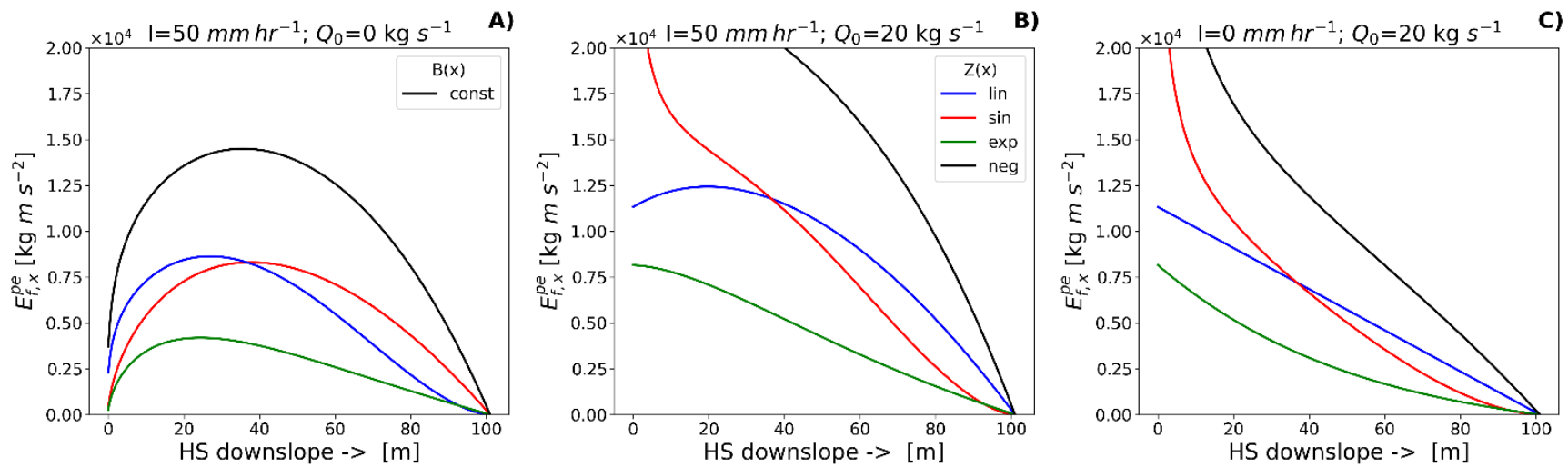

Figure 8: Distribution of potential energy $E_{f}^{p e}$ per unit length in [Joule $\mathrm{m}^{-1}$ ] a) without runon $\mathrm{Q}_{0}$ but with rainfall runoff accumulation $b$ ) with runon and runoff accumulation and c) with runon but without runoff accumulation

From these calculations, it appears that runoff accumulating systems show distinct energy conversion dynamics in comparison to runon systems, where runon outplays rainfall accumulation. Most strikingly, the accumulation of runoff in space energetically counteracts the depletion of geopotential gradients and leads to an energetic maximum. This stands in contrast to pure runon systems where energy is continuously depleted downslope. In between the two extremes, we observe transitions, which can result in local maxima, such as in the example of a linear slope $\left(\mathrm{z}_{\operatorname{lin}}(\mathrm{x})\right.$, Figure 8 (b)) depending on rainfall and runon intensities. 
The unrealistically high potential energies for $\mathrm{z}_{\mathrm{sin}}(\mathrm{x})$ and $\mathrm{z}_{\mathrm{neg}}(\mathrm{x})$ (Figure 8, panels (b) and (c)) within the first 20 meters of the hillslopes are due to our assumption that the energy gradient can be approximated by slope of terrain for the calculation of flow depth. The real gradient can be calculated by solution of the shallow water equations, which has been done in numerous studies and is out of scope for this analysis.

\subsubsection{Spatial patterns of power and dissipation}

In a second step, we calculated power and dissipation per unit flow length in $\mathrm{W} \mathrm{m}^{-1}$. We express $P_{f}$ power to create kinetic energy as per definition of Eq. (12) as the result of net boundary fluxes including precipitation. At this point we emphasize that $P_{f}$ must not be confused with the net kinetic energy flow $J_{f, n e t}^{k e}(x)$, which is related to the gradient of kinetic energy (compare Eq. (13)). In the standard model of energy conversion of surface runoff, potential energy is depleted, power $P_{f}$ therefore larger than zero, and kinetic energy is created, the divergence of kinetic energy flow being smaller than zero $\left(\mathrm{J}_{\mathrm{in}}{ }^{-}\right.$ $\mathrm{J}_{\mathrm{out}}<0$ ). Dissipation is the sum of the divergence of potential and kinetic energy flow, with the latter being a fraction of the former, which leads in turn to positive values for the dissipation of energy flow. Figure 9 shows the sensitivity of power and dissipation distributions $\left(P_{f}, J_{f, \text { net }}^{k e}\right.$ and $\left.D_{f}\right)$ to the climatic-topographic combinations as in section 4.1.1.

For all hillslope forms, our calculations show that a converging width function increases $P_{f}$ and a diverging width function decreases $P_{f}$ (Figure 9 (a)). If more rainfall falls at higher geopotentials (converging widths), the available potential energy to be converted is larger than on hillslopes with diverging widths, which accumulate the larger share of runoff at the lower end. We also note that a converging width results in a limitation of the growth of power in contrast to diverging and constant widths, which increase power without limitation of growth in downslope direction. Figure 9 (b) shows how the geopotential distribution $\mathrm{Z}(\mathrm{x})$ influences $P_{f}$. Exponential and sinusoidal distributions result in a point along the flow path with a maximum rate of energy conversion, whereas negative exponential and linear distributions unlimitedly increase power in downslope direction. For hillslope forms with a power limitation $(\mathrm{z}(\mathrm{x})=$ sinusoidal, exponential) converging widths lead to a power maximum that is relatively farther upstream than it is the case for diverging widths. Figure 9 (c) leads us to the conclusion that the rainfall intensity merely has a linear scale effect on the magnitude of $P_{f}$ and does not influence its relative spatial distribution.

380 Figure 9 panels (d) to (f) show results for the divergence of kinetic energy flow $J_{n e t}^{k e}$. With regard to the width function (Figure 9 (d)) converging widths increase $J_{n e t}^{k e}$, especially at the lower end where flow is highly concentrated and decrease $J_{\text {net }}^{k e}$ for diverging widths. Negative exponential and linear morphological forms show an increase in downslope direction, whereas exponential and sinusoidal forms limit the divergence of the flow of kinetic energy to a maximum at a certain flow distance (Figure 9 (e)). The latter distribution is especially interesting as we observe positive values, which we interpret as a loss of 
https://doi.org/10.5194/hess-2021-79

Preprint. Discussion started: 11 February 2021

(c) Author(s) 2021. CC BY 4.0 License.

385 kinetic energy in downslope direction $\left(\mathrm{J}_{\mathrm{in}}-\mathrm{J}_{\mathrm{out}}>0\right)$. Figure 9 (f) essentially repeats the results of Figure 9 (c), rainfall intensity scales the magnitude of energy flow.

In terms of dissipation, results (Figure 9 panels (g) to (i)) are almost identical to the results of $P_{f}$, which is of little surprise as for our examples kinetic energy flow is on average more than 1000 times smaller than potential energy flow. Recalling that dissipation $D_{f}$ in its essence is loss of free available energy per unit length, we put surface runoff into an energy-centered perspective. Our calculations show that all hillslope types with spatial mass accumulation will result in either spatially limited divergence of energy flow or an unlimited increase thereof in downstream direction. Depending on hillslope configuration, energy conversion processes can result in a spatial dissipation maximum. Certain types of hillslope forms spatially limit $D_{f}$ whereas others seemingly unlimitedly increase $D_{f}$. From our examples, hillslopes with sinusoidal and exponential distributions 395 of geopotential limit the accumulation of energy and lead to spatial maxima of dissipation. In contrast, hillslopes with linear and negative exponentially shaped topographies do not limit the creation of free energy and therefore do not lead to spatial maxima of $D_{f}$. Although not noticeable in our plots (Figure $9(\mathrm{~g})$ ), dissipation of converging hillslopes has decreased in comparison to constant width and has increased for diverging width. Converging flow increases the divergence of kinetic energy flow, or in other words more kinetic energy is accumulated in downstream direction for the same discharge. 

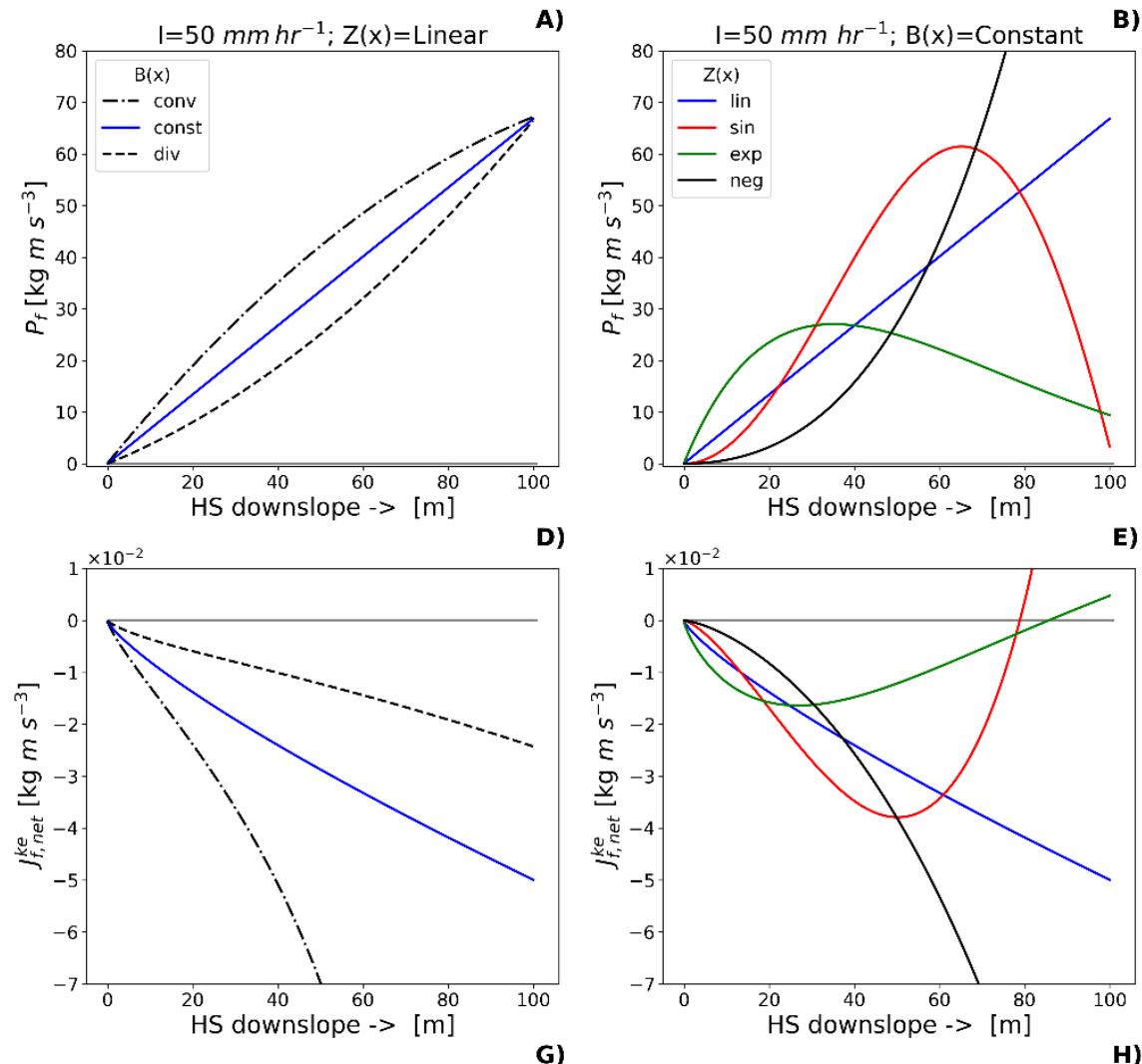

G)

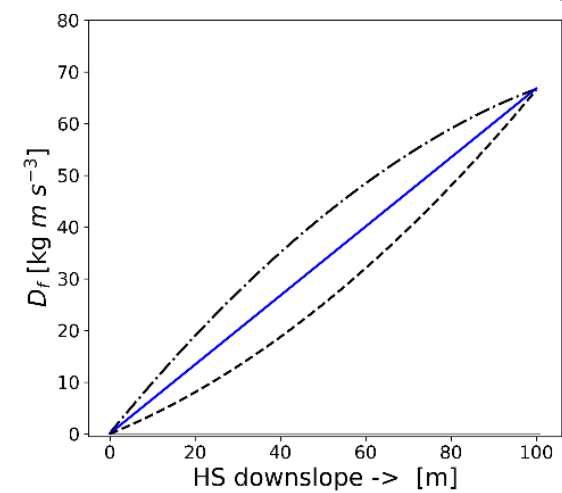

B)

E)

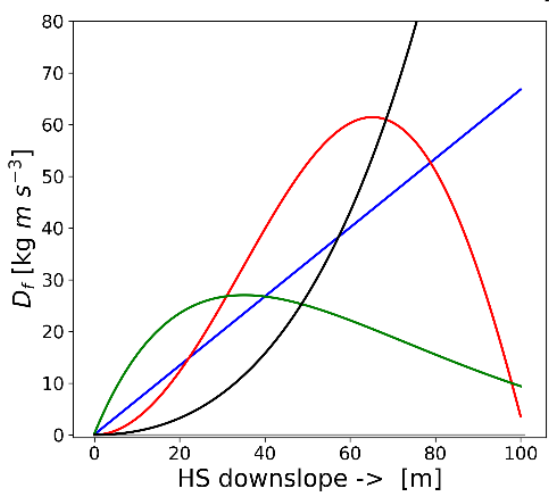

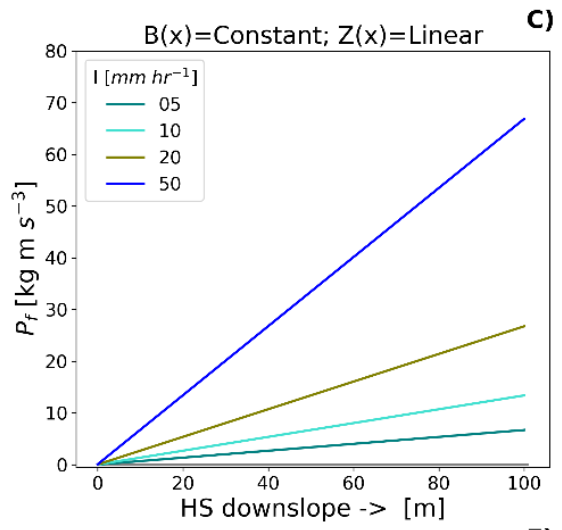

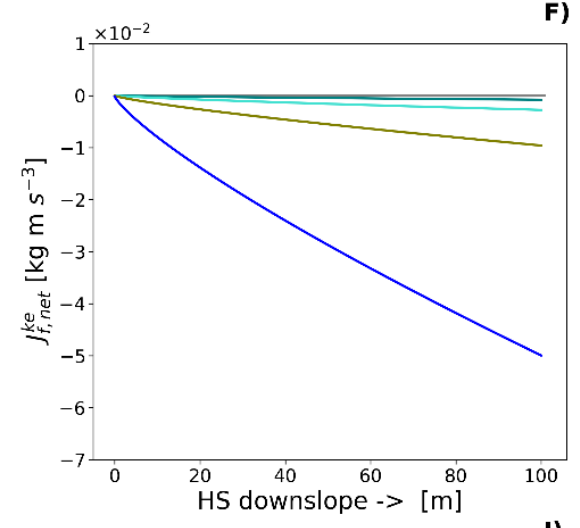

I)

C)

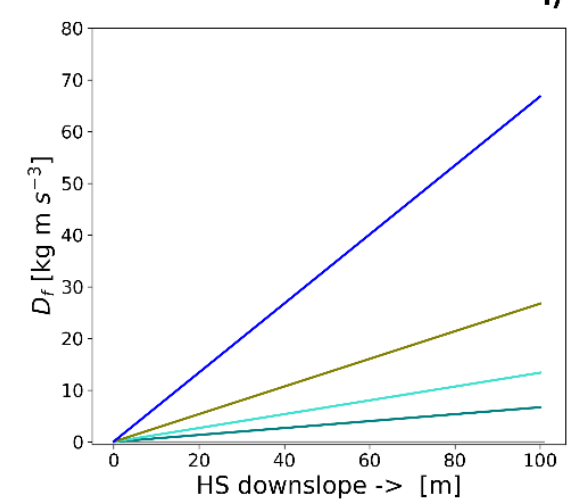

Figure 9: a) to c): Spatial distribution of power $P_{\mathrm{f}}$ to create kinetic energy. d) to f): Kinetic energy flow $J_{f, n e t}^{k e}$ and g) to i): Dissipation of energy flow in [Watt $\mathrm{m}^{-1}$ ]. Column 1: Rainfall intensity $50 \mathrm{~mm} \mathrm{hr}^{-1}$ and linear hillslope form but varying hillslope widths (constant, converging, diverging). Column 2: Rainfall intensity $50 \mathrm{~mm} \mathrm{hr} \mathbf{~}^{-1}$ and constant hillslope width but varying hillslope forms (linear, sinusoidal, exponential, negative exponential). Column 3: Linear hillslope form and constant hillslope width but varying rainfall intensities. 


\subsection{Influence of rills on dissipation}

From the previous section it became clear that energy conversion rates are distributed in space. For sheet flow we have shown that hillslope gradients along the flow path are the principal mechanism for redistribution of energy. In this section we analyse rill flow, which leads to redistribution of energy and therefore an alteration of energy conversion rates in space. In our thought experiment we allow a given amount of discharge to flow down on a given surface. We then calculated hydraulic sheet flow conditions and the equivalent hydraulic radius as well as the number of idealized rills (compare Figure 5) and plotted the result in Figure 10 (a). In this sense, a ratio $R_{R} / R_{S}$ above unity means an increase of flow velocity, while a ratio below unity would imply a decrease of rill flow velocity $v_{S}$ in comparison to sheet flow velocity $v_{R}$. Interestingly, smaller number of rills increase flow velocity and larger numbers of rills decrease flow velocity. We can also observe a critical rill number $m_{\text {crit }}$, which relates to the number of rills that would be necessary for equal velocities of rill and sheet flow $\left(v_{R}=v_{S}\right)$. By setting $R_{R}=R_{S}$ this number can be calculated to equal $m_{\text {crit }}=\frac{1}{2 * \pi} * \frac{b}{h_{s}}$ (Figure 10 (a)).

a)

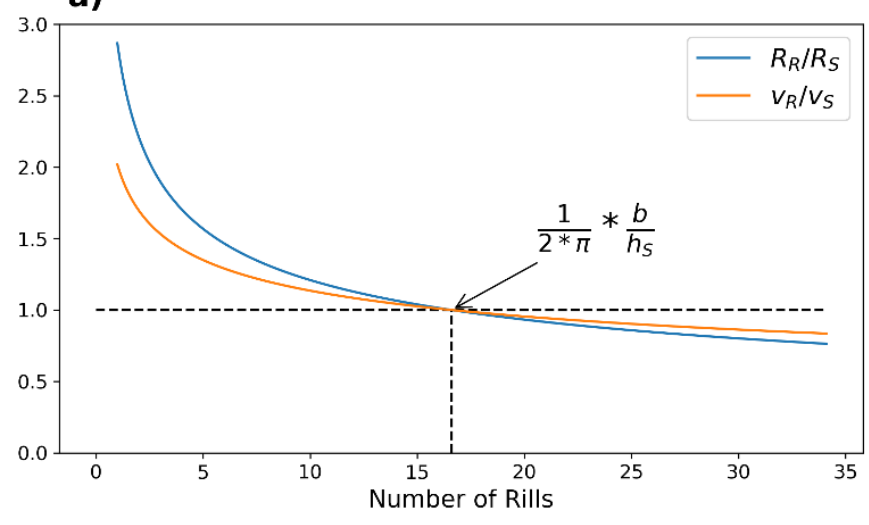

b)

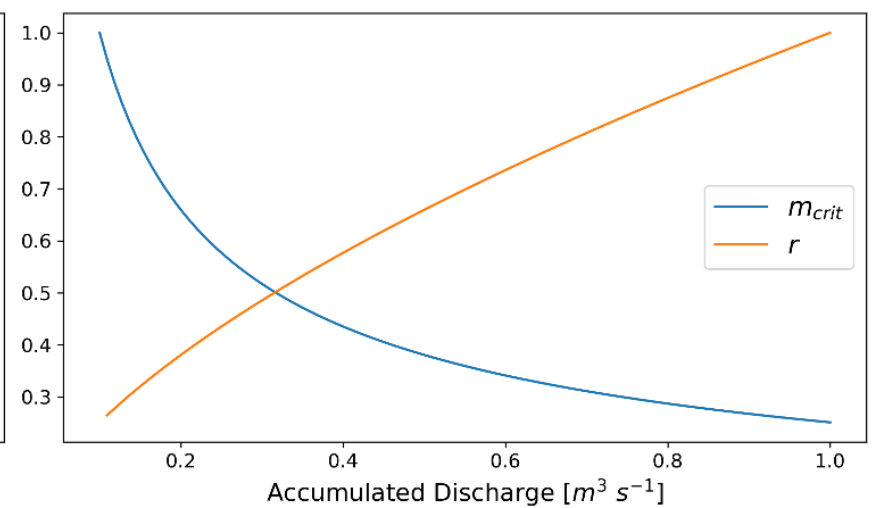

Figure 10: a) Ratios of hydraulic radius and velocity of rill flow and sheet flow; b) Relative critical rill number and relative radius for accumulation of discharge

As pointed out in the previous section, discharge accumulates on hillslopes and flow rates grow in downslope direction. We can therefore compute the critical rill number and the resulting rill radius $r$ as a function of growing discharge (Figure 10 (b)). For comparison, we plotted in Fig. 10 (b) the relative values of $r$ and $m_{\text {crit. }}$ We note that for an increase in discharge rill radius grows, while the critical number of rills decreases. So to say, many small rills form at the upstream beginning of the rill system, which transition into ever fewer yet larger rills. This sentence is true if $v_{R}$ is larger or equal to $v_{S}$, which implies a decrease of dissipation. Alternatively, one could say that in order to maintain a constant flow velocity along the flow path of a mass accumulating system, we would expect to see a convergence of many small rills into fewer larger ones. In conclusion, we state that rill flow is not necessarily leading to more kinetic energy per discharge volume. Only up to a limited number of rills, rill flow increases flow velocities and therefore kinetic energy. According to the first law of thermodynamics an increase in net kinetic energy flux would imply a decrease of dissipation as the total energy flux stays constant (Eq. (1)). Our results show 
that if velocity does not decrease in downstream direction (the direction of mass accumulation), rills converge into fewer larger

rills either maintaining constant velocities (if $m=m_{\text {crit }}$ ) or decreasing dissipative losses through increases in relative rill velocities (if $m<=m_{\text {crit }}$ ).

\subsection{Stream power and erosion}

As we have pointed out in Sec. 3.3, the distribution of forces acting on bed material is commonly estimated by Bangold's formula (Eq. (25)). We developed an equation, which specifically accounts for non-uniform mass distribution and is particularly important for mass accumulating systems (Eq. (16)) as it incorporates changes of kinetic energy.

To compare both equations we plotted in Figure 11 (a) a linear hillslope with a surface length $\mathrm{l}_{\mathrm{HS}}$ of 100 meters for slope angles from 1 degree to 82 degrees. The horizontal projected length decreases with increasing slope angle, which leads to less accumulation of rainfall for steeper slopes. Figure 11, panels (c) and (d) show the spatial distribution of potential and kinetic energy per unit flow length in Joule $\mathrm{m}^{-1}$. From comparison of the scales of both plots, it becomes clear that most potential energy is not converted into kinetic energy but is either transformed into some other form of free energy (e.g., pressure within bed material or sediment transport) or dissipated as heat and entropy. The plots in Figure 11 (c) show that potential energy peaks for all slope angles at a certain distance of projected flow length $x$ with different magnitude. Similarly, kinetic energy (Figure 11 (d)) peaks with different magnitudes as a function of slope angle but, contrarily to potential energy, steadily increases from top to foot of the hillslope. Figure 11, panel (b) shows how divergence of potential and kinetic energy flows influence distribution of dissipation in space. As kinetic energy is only a small fraction of potential energy, dissipation is driven by potential energy conversion. From our results, we can see that larger slope angles lead to larger values of dissipation, which is in line with Bangold's formula and underpins that Horton's assumption of a maximum force for the maximum value of the slope function is not justified.

We further deduct from these results that we have energetic and power maxima not only in space but also as a function of slope angle. There are two processes, which counteract in the formation of the energy budget: With an increase in slope angle the gradient that drives energy conversion increases, while at the same time. There is a decrease in the projected hillslope length and therefore the total amount of mass that falls onto the surface. Extracting the maximum value for each slope angle we note that potential energy peaks at roughly $45^{\circ}$ (Figure 11 (c)), yellow lines) but kinetic energy at $28^{\circ}$ (Figure 11 (d)), green lines). Divergence of dissipation increases with slope and largest values are obtained for steepest hillslopes (Figure 11 (b). 

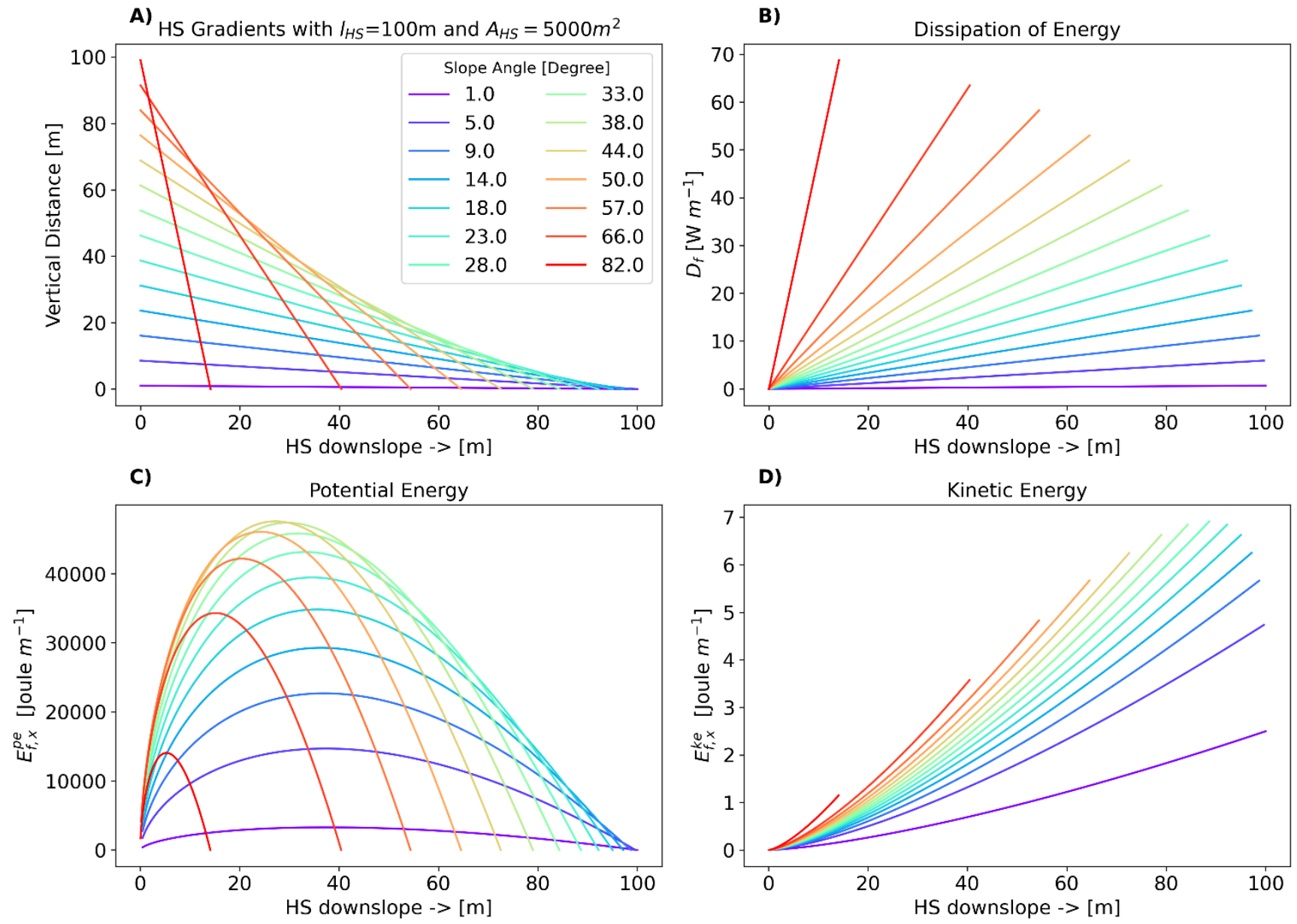

Figure 11: a) Linear, constant width hillslopes with length of 100 meters, width of 50 meters and increasing slope angles $\alpha$ in degree; b) Spatial distribution of dissipation per unit flow length in [Watt $\mathrm{m}^{-1}$ ]; c) Distribution of potential energy and d) of kinetic energy per unit flow length in [Joule $\left.\mathrm{m}^{-1}\right]$ as a function of slope angle.

With Eq. (12) and (13) we compute the divergence of the energy fluxes $P_{f}$ and $J_{f, \text { net }}^{k e}$ in Watt per unit length, which we then integrate (Eq. (20)) to obtain the total accumulated power $P$, kinetic energy flow $\mathrm{J}^{\mathrm{ke}}$ and dissipation $D$ in Watt (Figure 12) as a function of the flow path length. As the power $P$ is the potential energy that is converted per unit time into some other form of energy, $J^{k e}$ is the kinetic energy that is converted per unit time into some other form of energy. Comparison of the scales of Figure 12 (a) and Figure 12 (b) shows us once more that most of the potential energy does not convert into kinetic energy. Our results reveal that power and kinetic energy flow do not linearly relate to each other. Fig. 12 (a) shows that most of the potential energy per unit time is created for slope angles of $44^{\circ}$ and that most of the kinetic energy flows at a slope angle between $33^{\circ}$ to $38^{\circ}$ (Fig. 12 (b)). In fact, we analytically solved the system of equations for runoff accumulation for a fixed hillslope length 475 with varying slope angles and found that power $P$ should peak at $45^{\circ}$ and kinetic energy flow at $35^{\circ}$ (see Appendix A). We note here, that although the values of $J^{k e}$ are negative we speak of maximum instead of minimum values. In fact, negative 
values of kinetic energy flux represent the amount of energy that is extracted from some source of energy and converted into kinetic energy per unit time. We therefore state that kinetic energy flux increases to a maximum for a slope angle of $35^{\circ}$, while most energy is created and dissipated at a slope angle of $45^{\circ}$.

A)

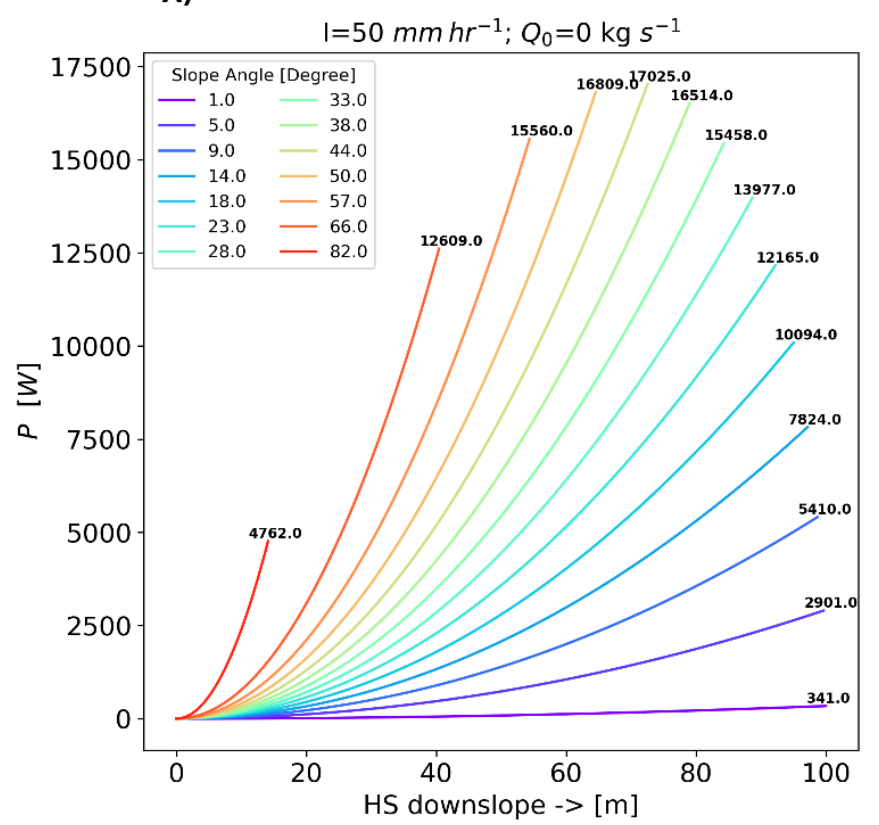

B)

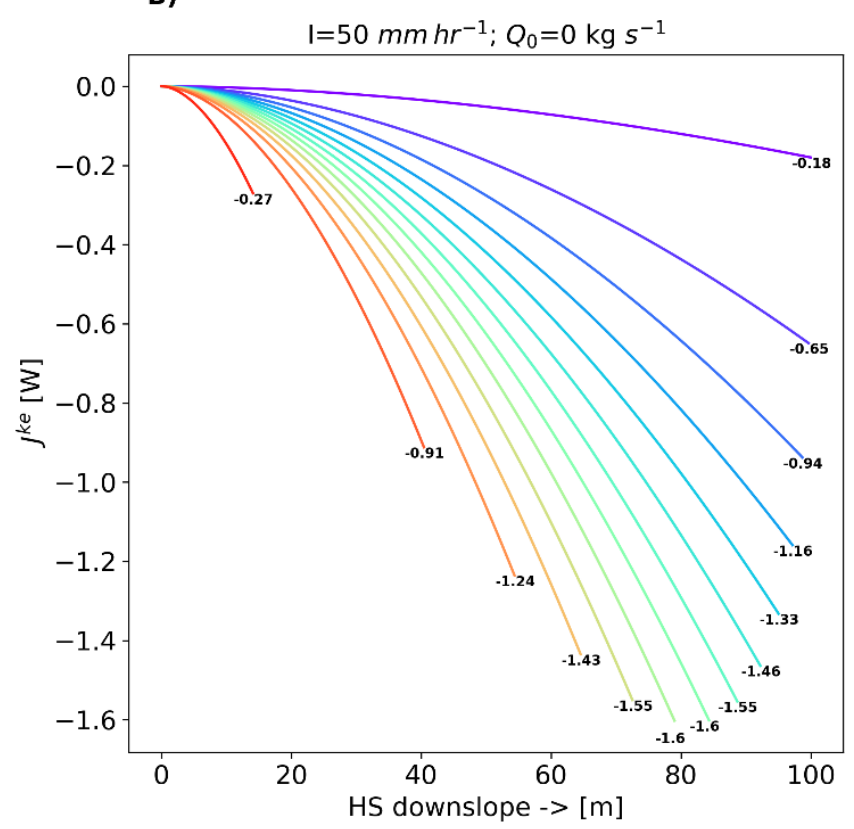

Figure 12: a) Accumulated power to convert potential into kinetic energy in Watt for a linear hillslope with constant surface area but varying slope angles from $1^{\circ}$ to $82^{\circ}$ b) Accumulated power to convert kinetic into some other type of energy in Watt for varying slope angles

As pointed out previously, dissipation can be approximated by four cases (see Table 2). For the calculations presented in Figure

11 and Figure 12 we applied the full equations, while in Figure 13, we present all four cases simultaneously for a single linear hillslope of the previously introduced hillslopes (Figure 11 (a)). We choose the hillslope with a slope angle of $45^{\circ}$ to include maximum divergence of potential energy fluxes and plotted the results of $P_{f}, J_{f, n e t}^{k e}$ and $D_{f}$ (Figure 13). As expected, the power to create kinetic energy is not affected by the different assumptions (Figure 13 (a)), the reduction of Eq. (16) to fewer terms has no influence on $P_{f}$. Similarly, as dissipation is almost completely the result of conversion of the potential energy, $D_{f}$ is neither influenced by the assumptions that reduce Eq. (16) (Figure 13 (c)). However, the reduction of the full equation for dissipation influences the result of $J_{f, n e t}^{k e}$ (Figure 13 (b)). Whereas the full equations lead to the largest divergence of kinetic energy flux, the assumption that velocity does not change in space reduces the outcome and the assumption that discharge does not change in space reduces it even further. If we assume that neither velocity nor discharge change in space, kinetic energy fluxes stay constant and divergence becomes zero. 

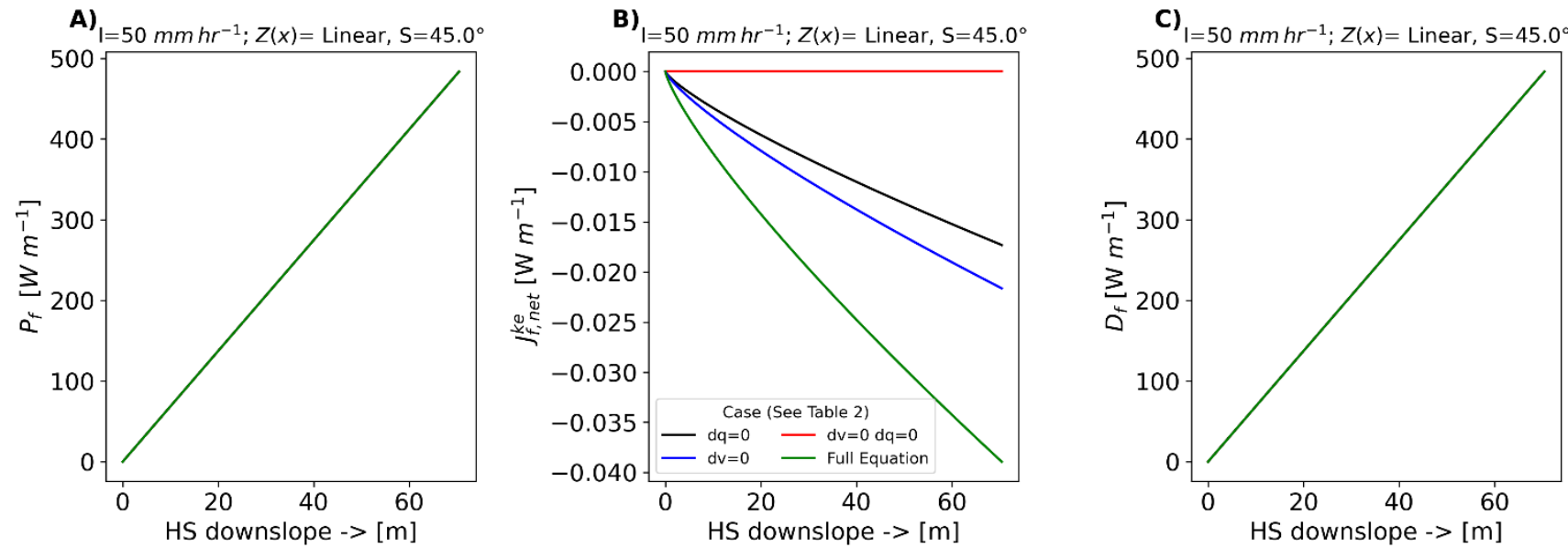

Figure 13: Calculation of $\boldsymbol{P}_{f}, J_{f, n e t}^{k e}$ and $D_{f}$ for a linear hillslope with $45^{\circ}$ slope angle and different assumptions (as per Table 2)

\section{Discussion}

In our analysis, we have conclusively shown that hillslopes as mass-accumulating systems show a distinctly different energetic behaviour in comparison to runon systems. The latter, e.g. a river does not necessarily lead to energetic maxima in space. As soon as mass accumulation overweighs runon, which is usually the case for hillslopes, we will observe spatial maxima of potential energy. For these systems, a trade-off between mass gain and geopotential loss along a runoff flow path leads to energy maxima in space. To calculate the spatial distribution of energy we used the relation between mass and discharge as stated by Manning's equation. With the resulting values of mass and velocity, we computed the power of surface runoff, which we set into a thermodynamic perspective through analysis of the energy balance and energy conversions. In this study we have exclusively focused on steady-state surface runoff on hillslopes, with the spatial accumulation and distribution dependent on rainfall intensity, hillslope morphology and width.

510 We have shown that only certain configurations of hillslope forms and widths lead to spatial power maxima (sinusoidal, exponential distributions of geopotential). This is interesting for the development of hillslope geomorphology, as we expect a metastable system to be power limited. As we have presented in our results, an unlimited increase in power theoretically implies an unlimited increase in dissipation as well as kinetic energy. This would lead to ever increasing forces that act on the bed material, eroding more material in downstream direction and should result in ever growing slope angles (similar to a negative exponential distribution). Obviously, this kind of landscape is not what we observe in nature and we conclude that there must be some power limiting feedback, which allows power to peak at a certain distance and further downstream fade out in order to reach meta-stability. These kinds of feedbacks are well known in natural systems (Kleidon, 2016) and their interplay is believed to lead to some dynamic equilibrium over time and the formation of structure (Bejan, 2010). 
In theory, this maximization of power and dissipation should have an observable physical significance for the runoff process. One hypothesis we propose, is that the distance where rills initiate, that is where the power is large enough to erode bed material, equals the point of maximum power of a meta-stable hillslope system. In many studies (Abrahams et al., 1994, Gomez et al., 2003), presence of rills is attributed to the minimization of dissipation, which we think is a rather incomplete picture. A surface geometry that is energetically more efficient, allows relatively more free energy to be conserved in the form of kinetic energy. However, our results indicate that the formation of rills cannot solely be attributed to minimization of dissipative losses. Depending on the precise rill geometries, the presence of rills can decrease or increase relative dissipation rates. First simple calculations presented in this study indicate that overall natural rill systems minimize dissipation, but we see the need of a hydraulically more thorough analysis of the transition of sheet- to rill flow. This study should account for energetic energy types which were neglected in this study, such as secondary currents and sediment transport. Furthermore, of the total energy balance, kinetic energy is only a minor contributor and most of the potential energy is always depleted into heat and entropy. We should also note at this point, that if over a certain area runoff accumulates in a more efficient way, there might be other areas where less water can accumulate, effectively decreasing efficiency. Considering these open questions and that only a small proportion of the total energy is represented by kinetic energy, it is questionable how big an impact the formation of rills really has on the total energy balance. We therefore think that the formation of rills is less an issue of the minimization of dissipation but rather a means of the redistribution of potential energy fluxes, which leads ultimately to a maximum of power in space and at the same time limits dissipation and erosion to achieve stability of the system. Our second hypothesis therefore is that rill formation is but one adaptation mechanism of hillslope surfaces to maximize and the same time limit power and dissipation in space. This conclusion is in line with the results by Rieke-Zapp et al. (2005) and Rodriguez-Iturbe et al. (1992) who studied flow in drainage systems and found that loss of free energy minimizes within the network. As the drainage network is only one part of the land surface, we claim however, that this theory cannot explain the appearance of the network in the first place.

In the last part of the study, we tried to close the loop and calculate the power of surface runoff as a function of slope as originally presented by Horton. In contrast to Horton's steady state assumption, which eliminates velocity from the equation,

545 we specifically accounted for divergence of potential and kinetic energy flow. We have shown that our approach leads to the same results of power but not for the divergence of the kinetic energy flux. This flux is important, as in a pure surface runoff system without sediment transport and small flow depths, it is the only fingerprint of the minimization of dissipation. Although approximately on a scale of 1000 times smaller than dissipation and power, the spatial distribution and its magnitude might hold the clues to understanding the formation of rills and even channel systems. For the particular hillslope in Section 4.3, we found that slope angles of roughly $35^{\circ}$ lead to a maximum kinetic energy flux, which might have some physically observable implication for bed shear stress. We think that more research is needed on the implications of spatial power rates distribution with regard to bed shear stress, but at least from an energy balance point of view we would expect that depending on the energy conversion dynamics, only a certain part of power effectively acts on the bed material. So far, we simply do not know which 
percentage of the free energy is converted into heat. We hypothesize that energy conversion dynamics are not linear, which means that depending on the type and amount of free energy, the percentage of dissipation varies. An indication of this theory are the different slope angles of maximum kinetic and maximum potential energy flow (compare Fig. 12). We saw that for our example of a linear hillslope maximum kinetic energy flow can be observed for $35^{\circ}$ slope angle while potential energy flow $\mathrm{P}$ peaks at $45^{\circ}$. This result implies that the change in kinetic energy is not proportional to the change in potential energy and the amount of free energy dissipated varies with the slope angle. Most energy per unit time is converted in a flow accumulating system such as hillslopes at $45^{\circ}$ but most kinetic energy per unit time is created on hillslopes with $35^{\circ}$ slope angles. From an energy point of view we could term hillslopes with a $35^{\circ}$ angle as most efficient, as they permit more potential energy per unit time to be conserved as kinetic energy per unit time than any other slope angle.

The presented analysis is more of a theoretical study, which might have most relevance in semi-arid and arid mountainous catchments, where Hortonian surface runoff is an important stream generation process (Dingmann, 2015). The inclusion of other hydrological processes on hillslopes, primarily infiltration will certainly influence our results but would go beyond the objectives of this study. There is evidence that infiltration is directly coupled to hillslope topography (Beven and Kirkby, 1979), and should be accounted for in a future analysis.

Furthermore, we already hinted at the inconsistency of approximating the energy gradient with the hillslope gradient as we have done in this analysis. As we have seen for some of the presented results, the slope gradient approximation leads to large uncertainties, especially when slopes become very small or very large. To overcome this issue, we intend to publish a second study, which will make use of numerical models, solving the momentum and mass balances and account for unsteady-state cases.

\section{Summary and Conclusion}

In this study we presented the formation of surface runoff on hillslopes from a thermodynamic point of view. The rate of energy conversion is different for runon and mass accumulating runoff systems. For steady-state runoff, we found that depending on mass distribution in space, there is a flow distance with maximum dissipation rate. Distribution of mass itself is a result of the erosion and deposition of sediment, shaping the surface and creating geopotential gradients. We therefore believe that this point of maximum energy flux should have some physical meaning and might be related to the initiation of rill flow, that is the accumulation of surface runoff in eroded micro channels. Depending on geometry and friction losses, these micro

580 channels might allow more potential energy to be converted into kinetic energy and possibly other forms of free energy such as work for sediment transport or secondary currents, decreasing overall dissipation whilst increasing free energy locally. More kinetic energy leads to a depletion of the potential energy gradient and therefore limits the creation of ever more kinetic energy of the main flow direction. Similarly, more erosion and sediment transport deplete the driving geopotential gradient. Therefore, in the context of geomorphological development we conclude that flow accumulation serves as a limitation of power and is an 585 expression of feedback to reach dynamic equilibrium. Over time power rates have to peak at a certain distance as an expression of counteracting energy conversion processes. Depending on local physical characteristics such as bedrock material, soil 
development and climate, scales may vary but a general trend towards maximum energy conversion rates should be observable. Apart from spatial power rate maxima, we found that the maximum total power of a hillslope is a function of the slope angle. For a linear hillslope, power is largest for slope angles of $45^{\circ}$, while the most efficient runoff with maximization of kinetic energy flux occurs on a slope of $35^{\circ}$. This result indicates that minimization of dissipation and maximization of power are not equivalent for surface runoff processes.

\section{Author contribution}

S. Schroers conceptualized, conducted the analysis and wrote the study. O. Eiff conceptualized and supervised the hydraulic concepts. A. Kleidon reviewed and edited the thermodynamic concepts. J. Wienhöfer contributed to the formulation and visualization of the concepts and results. E. Zehe oversaw the study as mentor.

\section{Competing interests}

The authors declare that they have no conflict of interest.

\section{References}

Abrahams, A. D.; Parsons, J. D.; Wainwright, J. (1994): Resistance to overland flow on semiarid grassland and shrubland hillslopes, Walnut Gulch, southern Arizona. In: Journal of Hydrology (156), S. 431-446.

Achten, Wouter M. J.; Dondeyne, Stefaan; Mugogo, Samweli; Kafiriti, Elly; Poesen, Jean; Deckers, Jozef; Muys, Bart (2008): Gully erosion in South Eastern Tanzania: spatial distribution and topographic thresholds. In: Zeit fur Geo 52 (2), S. 225-235. DOI: 10.1127/0372-8854/2008/0052-0225.

Bangold, R. A. (1966): An approach to the sediment transport problem from general physics. In: US. geol. Surv. Prof. Paper 605 (422-I).

Bejan, A.; Lorente, S. (2010): The constructal law of design and evolution in nature. In: Philosophical transactions of the Royal Society of London. Series B, Biological sciences 365 (1545), S. 1335-1347. DOI: 10.1098/rstb.2009.0302.

Berger, C.; Schulze, M.; Rieke-Zapp, D. H.; Schlunegger, F. (2010): Rill development and soil erosion: a laboratory study of slope and rainfall intensity. In: Earth. Surf. Process. Landforms (35), S. 1456-1467.

610 Berkowitz, B.; Zehe, E. (2020): Surface water and groundwater: unifying conceptualization and quantification of the two “water worlds". In: Hydrol. Earth Syst. Sci. 24 (4), S. 1831-1858. DOI: 10.5194/hess-24-1831-2020.

Berne, A.; Uijlenhoet, R.; Troch, P. A. (2005): Similarity analysis of subsurface flow response of hillslopes with complex geometry. In: Water Resour. Res. 41 (9). DOI: 10.1029/2004WR003629. 
Betson, R. P. (1964): What is watershed runoff? In: Journal of Geophysical Research (69-8), S. 1541-1552. DOI: 10.1029/JZ069i008p01541.

Beven, K. J.; Kirkby, M. J. (1979): A physically based, variable contributing area model of basin hydrology. In: Hydrological Sciences Bulletin 24 (1), S. 43-69. DOI: 10.1080/02626667909491834.

Dingman, S. L. (2015): Physical hydrology. 3. ed. Long Grove, Ill.: Waveland Press.

Emmett, W. W. (1970): The Hydraulics of Overland Flow on Hillslopes. In: US. geol. Surv. Prof. Paper (662).

Faulkner, Hazel (2008): Connectivity as a crucial determinant of badland morphology and evolution. In: Geomorphology 100 (1-2), S. 91-103. DOI: 10.1016/j.geomorph.2007.04.039.

Favis-Mortlock, F.; Boardman, J.; Parsons, A. J.; Lascelles, B. (2000): Emergence and erosion: a model for rill initiation and development. In: Hydrol. Process. (14), S. 2173-2205.

Gomez, J. A.; Darboux, F.; Nearing, M. A. (2003): Development and evolution of rill networks under simulated rainfall. In: Water Resour. Res. (6).

Horton, R. E. (1945): Erosional development of streams and their drainage basins; Hydrophysical approach to quantitive morphology. In: Bulletin of the Geological Soc. of America (56), S. 275-370.

Howard Alan D. (1990): Theoretical Model of Optimal Drainage Networks. In: Water Resour. Res. (9), S. 2107-2117.

Ibbitt, R. P. (1997): Evaluation of optimal channel network and river basin heterogeneity concepts using measured flow and channel properties. In: Journal of Hydrology (196), S. 119-138.

Ijjasz Vasquez, E. J.; Bras, R. L.; Rodriguez-Iturbe, I.; Rigon, R.; Rinaldo, A. (1993): Are river basins optimal channel networks? In: Advances in Water Resources (16), S. 69-79.

Kirkby, M. J. (1971): Hillslope process-response models based in the continuity equation. In: Special Publication Institute of British Geographers (3), S. 15-30.

635 Kleidon, A. (2016): Thermodynamic foundations of the Earth system. New York NY: Cambridge University Press.

Kleidon, A.; Renner, M.; Porada, P. (2014): Estimates of the climatological land surface energy and water balance derived from maximum convective power. In: Hydrol. Earth Syst. Sci. 18 (6), S. 2201-2218. DOI: 10.5194/hess-18-22012014.

Kleidon, A.; Zehe, E.; Ehret, U.; Scherer, U. (2013): Thermodynamics, maximum power, and the dynamics of preferential river flow structures at the continental scale. In: Hydrol. Earth Syst. Sci. 17 (1), S. 225-251. DOI: 10.5194/hess-17225-2013.

Leopold, Luna B., Langbein, Walter B. (1962): The concept of entropy in landscape evolution. In: US. geol. Surv. Prof. Paper (500-A).

Loritz, R.; Kleidon, A.; Jackisch, C.; Westhoff, M.; Ehret, U.; Gupta, H.; Zehe, E. (2019): A topographic index explaining hydrological similarity by accounting for the joint controls of runoff formation. In: Hydrol. Earth Syst. Sci. 23 (9), S. 3807-3821. DOI: 10.5194/hess-23-3807-2019. 
Paik, K.; Kumar, P. (2010): Optimality approaches to describe characteristic fluvial patterns on landscapes. In: Philosophical transactions of the Royal Society of London. Series B, Biological sciences 365 (1545), S. 1387-1395. DOI: 10.1098/rstb.2009.0303.

Pandey, A.; Himanshu, S. K.; Mishra, S. K.; Singh, V. P. (2016): Physically based soil erosion and sediment yield models revisited. In: CATENA 147, S. 595-620. DOI: 10.1016/j.catena.2016.08.002.

Parsons, A. J.; Abrahams, A. D.; Luk, S. H. (1990): Hydraulics of interrill overland flow on a semi-arid hillslope, Arizona. In: Journal of Hydrology (117), S. 255-273.

Rieke-Zapp, D. H.; Nearing, M. A. (2005): Slope shape effects on erosion: a laboratory study. In: Soil Sci. Soc. Am. J. (69), S. $1463-1471$.

Rinaldo, A. (1999): Hydraulic networks in nature. In: Journal of Hydraulic Research 37 (6), S. 847-859. DOI: 10.1080/00221689909498515.

Rinaldo, A.; Rodriguez-Iturbe, I.; Rigon, R.; Bras, R. L.; Ijjasz-Vasquez, E.; Marani, A. (1992): Minimum energy and fractal structures of drainage networks. In: Water Resour. Res. (9), S. 2183-2195.

Rodriguez-Iturbe, I.; Marani, M.; Rigon, R.; Rinaldo, A. (1994): Self-organized river basin landscapes: Fractal and multifractal characteristics. In: Water Resour. Res. 30 (12), S. 3531-3539. DOI: 10.1029/94WR01493.

Rodriguez-Iturbe, I.; Rinaldo, A.; Rigon, R.; Bras, R. L.; Marani, A.; Ijjasz-Vasquez, E. (1992): Energy dissipation, runoff production, and the threedimensional structure of river basins. In: Water Resour. Res. (4), S. 1095-1103.

Shao, Xuejun; Wang, Hong; Hu, Huiwu (2005): Experimental and modeling approach to the study of the critical slope for the initiation of rill flow erosion. In: Water Resour. Res. 41 (12). DOI: 10.1029/2005WR003991.

Thorn, C. E.; Welford, M. R. (1994): The Equilibrium Concept in Geomorphology. In: Annals of the Association of American Geographers 84 (4), S. 666-696. Online verfügbar unter http://www.jstor.org/stable/2564149.

Troch, Peter A.; van Loon, Arnaut H.; Hilberts, Arno G. J. (2004): Analytical solution of the linearized hillslope-storage Boussinesq equation for exponential hillslope width functions. In: Water Resour. Res. 40 (8). DOI: 10.1029/2003WR002850.

West, G. B.; Brown, J. H.; Enquist, B. J. (1997): A general model for the origin of allometric scaling laws in biology. In: Science (New York, N.Y.) 276 (5309), S. 122-126. DOI: 10.1126/science.276.5309.122.

Yang, C. T. (1971): Potential Energy and Stream Morphology. In: Water Resour. Res. (7), S. 311-322.

Zamir, M. (1976): Optimality principals in arterial branching. In: J. theor. Biol. (62), S. 227-251.

675 Zehe, E.; Ehret, U.; Blume, T.; Kleidon, A.; Scherer, U.; Westhoff, M. (2013): A thermodynamic approach to link selforganization, preferential flow and rainfall-runoff behaviour. In: Hydrol. Earth Syst. Sci. 17 (11), S. 4297-4322. DOI: 10.5194/hess-17-4297-2013.

Zehe, E.; Sivapalan, M. (2009): Threshold behaviour in hydrological systems as (human) geo-ecosystems: manifestations, controls, implications. In: Hydrol. Earth Syst. Sci. (13), S. 1273-1297. 
https://doi.org/10.5194/hess-2021-79

Preprint. Discussion started: 11 February 2021

(C) Author(s) 2021. CC BY 4.0 License.

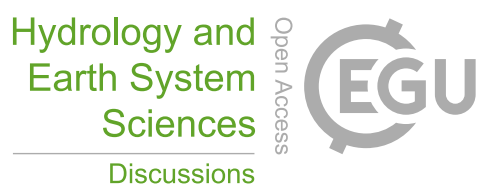

680 Zhang, Z.; Savenije, H. G. (2018): Thermodynamics of saline and fresh water mixing in estuaries. In: Earth Syst. Dynam. 9 (1), S. 241-247. DOI: 10.5194/esd-9-241-2018. 


\section{Appendix A}

685 Derivation of maximum power angles for $\mathrm{P}, \mathrm{J}^{\mathrm{ke}}$ and $\mathrm{D}$.

For varying slope angles $\alpha$ and constant hillslope length the accumulated discharge through precipitation is:

$Q(x)=\int_{0}^{x} P_{e f f} * b(x) d x$

Which for constant width $\mathrm{b}$ and the horizontal projection of the hillslope length $\mathrm{l}_{\mathrm{hs}}$ becomes:

$Q\left(x=l_{h s}\right)=P_{\text {eff }} * b * l_{h s} * \cos \alpha$

690 The second formula relates the flow depth, calculated by Manning Strickler to the varying slope angles:

$d\left(x=l_{h s}\right)=\left(\frac{Q\left(x=l_{h s}\right) * n}{b * \tan ^{0.5} \alpha}\right)^{0.6}$

which becomes with the formulation of (A1) for accumulated discharge:

$d\left(x=l_{h s}\right)=\left(\frac{P_{e f f} * b * l_{h s} * \cos \alpha * n}{b * \tan ^{0.5} \alpha}\right)^{0.6}=n^{0.6} * P_{e f f}^{0.6} * l_{h s}^{0.6} * \cos ^{0.6} \alpha * \tan ^{-0.3} \alpha$

We now use these equations to calculate power $\mathrm{P}$ and maximum kinetic energy flow $\mathrm{J}^{\mathrm{ke}}$ as a function of slope angle.

\section{Power $\mathbf{P}\left(\mathbf{x}=\mathrm{I}_{\mathrm{hs}}\right)$}

The total accumulated power in [W] at the end of the hillslope is:

$P\left(x=l_{h s}\right)=\rho * g * Q\left(l_{h s}\right) * h$

where $\mathrm{h}$ is the average height at which rainfall falls onto the hillslope:

$h=0.5 * l_{h s} * \sin \alpha$

700 With Eq. (A1) we obtain:

$P\left(x=l_{h s}\right)=\rho * g * P_{\text {eff }} * b * l_{h s} * \cos \alpha * 0.5 * l_{h s} * \sin \alpha$

Eq. (A3) shows a maximum at the maximum of $\boldsymbol{f}_{P}(\alpha)=\cos \alpha * \sin \alpha$, which is at a slope angle of $45^{\circ}$ or $\pi / 4$ radians.

\section{Kinetic Energy Flow $\mathbf{J}^{\mathrm{ke}}$}

Similarly, we can express accumulated kinetic energy flow at the end of the hillslope in [W] as a function of slope:

$\mathrm{J}^{\mathrm{ke}}\left(x=l_{h s}\right)=\frac{\rho}{2} * v\left(l_{h s}\right)^{2} * Q\left(l_{h s}\right)=\frac{\rho}{2} * Q\left(l_{h s}\right)^{3} *\left(d\left(l_{h s}\right) * b\right)^{-2}$

With Eq. (A1) and Eq. (A2):

$J^{k e}\left(x=l_{h s}\right)=\frac{\rho}{2} *\left(P_{e f f} * b * l_{h s} * \cos \alpha\right)^{3} *\left(n^{0.6} * P_{e f f}^{0.6} * l_{h s}^{0.6} * \cos ^{0.6} \alpha * \tan ^{-0.3} \alpha * b\right)^{-2}$

$=\frac{\rho}{2} * n^{-1.2} * P_{e f f}^{1.8} * b * l_{h s}^{1.8} * \cos ^{1.8} \alpha * \tan ^{0.6} \alpha$

This equation shows a maximum at the maximum of $f_{J}=\cos ^{1.8} \alpha * \tan ^{0.6} \alpha$, which is the case for a slope angle of $35^{\circ}$. 